Research Paper

\title{
SEL120-34A is a novel CDK8 inhibitor active in AML cells with high levels of serine phosphorylation of STAT1 and STAT5 transactivation domains
}

\begin{abstract}
Tomasz Rzymski ${ }^{1, *}$, Michał Mikula ${ }^{2,}{ }^{*}$, Eliza Żyłkiewicz ${ }^{1}$, Agnieszka Dreas ${ }^{1}$, Katarzyna Wiklik$^{1}$, Aniela Gołas ${ }^{1}$, Katarzyna Wójcik ${ }^{1}$, Magdalena Masiejczyk ${ }^{1}$, Anna Wróbel ${ }^{1}$, Izabela Dolataㄹ, Agata Kitlińska ${ }^{1}$, Małgorzata Statkiewicz², Urszula Kuklinska², Krzysztof Gorycaㄹ, ${ }^{2}$ ukasz Sapała ${ }^{1}$, Aleksandra Grochowska ${ }^{3}$, Aleksandra Cabaj ${ }^{2,4}$, Małgorzata Szajewska-Skuta ${ }^{1}$, Ewelina Gabor-Worwa' ${ }^{1}$ Katarzyna Kucwaj ${ }^{1}$, Arkadiusz Białas ${ }^{1}$, Adam Radzimierski ${ }^{1}$, Michał Combik ${ }^{1}$, Jakub Woyciechowski ${ }^{1}$, Maciej Mikulski, Renata Windak ${ }^{1}$, Jerzy Ostrowski' ${ }^{2,3}$ and Krzysztof Brzózka ${ }^{1}$

${ }^{1}$ R\&D Department, Selvita S.A., Kraków, Poland

${ }^{2}$ Department of Genetics, Maria Sklodowska-Curie Memorial Cancer Center, Warsaw, Poland

${ }^{3}$ Department of Gastroenterology, Hepatology and Clinical Oncology, Medical Center for Postgraduate Education, Warsaw, Poland

${ }^{4}$ Laboratory of Bioinformatics, Nencki Institute of Experimental Biology, Warsaw, Poland

*These authors have contributed equally to this work

Correspondence to: Krzysztof Brzózka, email: krzysztof.brzozka@selvita.com

Keywords: CDK8 mediator, kinase inhibitor, STAT5, AML, leukemia stem cells

Received: August 04, $2016 \quad$ Accepted: March 09, $2017 \quad$ Published: April 04, 2017

Copyright: Rzymski et al. This is an open-access article distributed under the terms of the Creative Commons Attribution License (CC-BY), which permits unrestricted use, distribution, and reproduction in any medium, provided the original author and source are credited.
\end{abstract}

\section{ABSTRACT}

Inhibition of oncogenic transcriptional programs is a promising therapeutic strategy. A substituted tricyclic benzimidazole, SEL120-34A, is a novel inhibitor of Cyclin-dependent kinase 8 (CDK8), which regulates transcription by associating with the Mediator complex. X-ray crystallography has shown SEL120-34A to be a type I inhibitor forming halogen bonds with the protein's hinge region and hydrophobic complementarities within its front pocket. SEL120-34A inhibits phosphorylation of STAT1 S727 and STAT5 S726 in cancer cells in vitro. Consistently, regulation of STATs- and NUP98-HOXA9- dependent transcription has been observed as a dominant mechanism of action in vivo. Treatment with the compound resulted in a differential efficacy on AML cells with elevated STAT5 S726 levels and stem cell characteristics. In contrast, resistant cells were negative for activated STAT5 and revealed lineage commitment. In vivo efficacy in xenotransplanted AML models correlated with significant repression of STAT5 S726. Favorable pharmacokinetics, confirmed safety and in vivo efficacy provide a rationale for the further clinical development of SEL12034A as a personalized therapeutic approach in AML.

\section{INTRODUCTION}

Two paralog kinases: CDK8 and CDK19, reversibly associate with the Mediator complex and form its key regulatory unit $[1,2]$. Activities of CDK8 and CDK 19 have been implicated in sustained proliferation and viability of cancer cell lines, probably by modulation of various gene expression programs. Currently, there is an interest in therapeutic targeting of these kinases in cancer, particularly in acute myeloid leukemia (AML) $[3,4]$. Pharmacological inhibition of CDK8 and CDK19 by the steroidal alkaloid Cortistatin A (CA), deregulates expression of tumor suppressors and lineage-controlling genes in AML and results in suppressed growth of cancer cells [4]. Surprisingly, several reports have indicated that selective CDK8 inhibitors were inactive on colorectal 
cancer (CRC) cell lines with amplification of CDK8, which were previously characterized as being sensitive to CDK8 gene silencing $[5,6]$. CDK8 activity is involved in $\mathrm{WNT} / \beta$-catenin signaling [7], the serum response network [8], p53 pathway [9], p21 regulated transcription [10], Notch signaling [11] and a hypoxia response [12]. Several CDK8-selective probes displayed inhibitory activity for the $\mathrm{WNT} / \beta$-catenin pathway in vitro in CRC cell lines $[10,13,14]$. In contrast, transcriptional profiling of AML cells treated with $\mathrm{CA}$, revealed significant induction of super-enhancer (SE) associated genes [4]. Effects of CA on RNA polymerase II (RNAP II) transcription in the HCT-116 CRC line were rather modest and involved genes implicated in inflammation, growth, and metabolic regulation [6]. These effects only partially overlap with transcriptional profiling of CDK8 and CDK19 knockdown cells and the response to CA in AML cells $[12,15]$. Such discrepancies were further discussed as a result of differences between kinase and scaffolding functions of CDK8 and CDK19 within the Mediator complexes [6].

Several substrates of CDK8 kinase have been identified $[11,16-18]$ and the majority of CDK8 inhibitors have been shown to consistently repress phosphorylation of the transactivation domains of STATs $[4,5,14]$.

Here, we report characterization of a novel ATPcompetitive and selective CDK8 inhibitor SEL120-34A, with an unusual binding mode compared to other CDK8 inhibitors [19]. In keeping with previous studies, SEL12034A inhibited phosphorylation of STAT1 at serine 727 (S727) and STAT5 at serine 726 (S726) in AML cells. Efficacy studies of SEL120-34A and other structurally non-related CDK8 inhibitors in AML cells indicated differential activity on cells positive for phosphorylated STAT1 S727 and STAT5 S726. Transcriptional profiling of SEL120-34A effects revealed selective activity on genes regulated by STATs and NUP98-HOXA9 signaling. High bioavailability after oral administration and metabolic stability enabled in vivo efficacy studies, which indicated AML tumor growth inhibition at safe doses. Taken together, SEL120-34A is a first in class CDK8 inhibitor which has advanced into preclinical development and may be a convenient tool for further biological studies.

\section{RESULTS}

\section{SEL120-34A is a novel selective CDK8 inhibitor}

Structure-based drug design led to the synthesis of a substituted tricyclic benzimidazole SEL120-34A as a novel CDK8 inhibitor (Figure 1A). The detailed synthesis pathway is available in the supplementary methods. We determined that SEL120-34A inhibited kinase activities of $\mathrm{CDK} 8 / \mathrm{CycC}$ and $\mathrm{CDK} 19 / \mathrm{CycC}$ complexes with an $\mathrm{IC}_{50}$ of $4.4 \mathrm{nM}$ and $10.4 \mathrm{nM}$, respectively (Figure 1B). The dissociation constant $(\mathrm{Kd})$ for the CDK8 protein was estimated at $3 \mathrm{nM}$ (Supplementary Figure 1). These values were comparable with two other, structurally unrelated CDK8 inhibitors, namely Senexin B (SNX2-1-165 from patent WO-2014134169) [20], and CCT251545 [21] (Figure $1 \mathrm{~B}$ and Supplementary Figure 1). By contrast, SEL120-34A did not significantly inhibit other members of the CDK family in a single point inhibition assay, namely CDK1, 2, $4,6,5,7$ in vitro (Figure 1C), with the exception of CDK9, however a calculated $\mathrm{IC}_{50} 1070 \mathrm{nM}$, indicated an over 200 fold selectivity against this kinase (Supplementary Figure 2).

\section{Binding mode of SEL120-34A}

To understand the binding mode of SEL120-34A to CDK8, we resolved a $2.8-\AA$ crystal structure of the CDK8/ CycC/SEL120-034A complex. We observed inhibitor binding to the kinase in DMG-in conformation, similar to the previously reported structures of $\mathrm{CDK} 8 / \mathrm{CycC}$ alone, complexed with CA or in complex with a small molecule inhibitor of WNT signaling [4, 14, 21, 22]. SEL120-34A interacts with the ATP binding site of CDK8 in a type I inhibitor manner by forming several types of interactions with the protein (Figure 1D). Two bromine atoms form halogen bonds with the carbonyl group of Asp 98 and the backbone's NH of Ala 100. Additionally, one bromine atom interacts with the $\pi$-system of Tyr 99 . The piperazine moiety is stacked between side chains of Tyr 32 and Asn 156. Furthermore, its amine moiety forms the following interactions: (i) an ionic interaction with a carboxyl group of Asp 173, (ii) a hydrogen bond with a side chain carbonyl group of Asn 156 and (iii) a cation- $\pi$ system interaction with Tyr 32. The nitrogen atom of the benzimidazole core forms a water mediated hydrogen bond with Lys 52 . The methyl group of SEL120-34A points toward the gatekeeper residue (Phe 97) and Ile 79. The tricyclic benzimidazole core forms hydrophobic contacts with "the floor" (Ala 100, Leu 158, Ala 172) and "the ceiling" (Val 27, Gly 28, Val 35, Ala 50) of the ATP binding pocket. Additionally, a partially aliphatic ring of the benzimidazole core forms contacts with Arg 356 that constitutes the side wall of the pocket. The latter is a key for selectivity, as Arg 356 is a part of a C-terminal extension unique for CDK8. The observed protein-ligand interaction pattern obeys rules for long residence time, namely $\mathrm{H}$-bond formation with the hinge region (here exhibited by halogen bonding) and hydrophobic complementarities within the front pocket [22].

\section{SEL120-34A inhibits phosphorylation of STAT1 S727 and STAT5 S726}

We evaluated the affinity of SEL120-34A to CDK8 in KG-1 AML cell lysates using desthobiotin-ATP probes. SEL120-34A could effectively bind to CDK8 in a dosedependent manner (at 1- $100 \mathrm{nM}$ concentration range) as shown by competition with ATP- analogue probes (Figure 2A). CDK8 kinase specifically targets S727 phosphorylation at the transactivation domain of STAT1 
upon interferon $\gamma$ (IFNg) treatment [17]. This modification is not required for the formation of STAT dimers, however it was found to trigger full transcriptional activity of STAT proteins [23]. To test if SEL120-34A alters S727 phosphorylation, we first treated HCT-116 CRC cells with increasing doses of IFNg or interferon $\alpha / \beta$ (INFa). As expected, IFN stimulation enhanced phosphorylation of STAT1 S727 and tyrosine 701 (Y701) (Supplementary Figure $3 \mathrm{~A}$ and $3 \mathrm{~B}$ ). We next challenged HCT-116 cells with IFNa or IFNg for 4 hours in the presence of increasing concentrations of SEL120-34A, which resulted in a dosedepended inhibition of S727, that was more pronounced after IFNg treatment (Figure 2B and Supplementary Figure 3C). A similar reduction in STAT1 S727 phosphorylation was observed after treatment with the pan-CDK inhibitor Flavopiridol. The C-terminal repeat domain (CTD) of RNAP II phosphorylation at S2 and S5 [24, 25] was not affected by up to $2.5 \mu \mathrm{M}$ of the compound in cells
(Supplementary Figure 4), indicating selectivity over CDK9, whereas Flavopiridol was active towards RNAP II.

The relationship with Janus kinase (JAK)-dependent activation of STATs was further studied in SET-2 cells which carry the JAK2 V617F mutation [26]. JAKs activate STATs by phosphorylating their conserved C-terminal tyrosine residues. Treatment with Ruxolitinib, a specific inhibitor of JAK2, resulted in the inhibition of STAT5 Y694 phosphorylation, whereas S726 was unaffected. In contrast, SEL120-34A exhibited activity towards S726, but not Y694 (Figure 2C).

\section{SEL120-34A inhibits mitogen- induced expression of immediate early response (IER) genes}

Earlier studies on the CRC cell line HCT-116 provided evidence on CDK8 involvement in IER gene<smiles>CCOCCN1CCNCC1c1nc2c(C)c(Br)c(Br)c3c2n1CCC3</smiles>

$B$

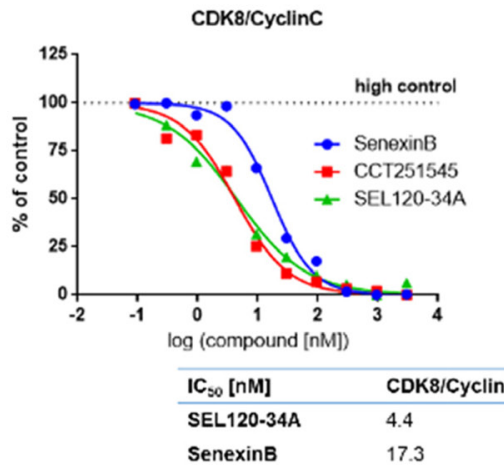

D
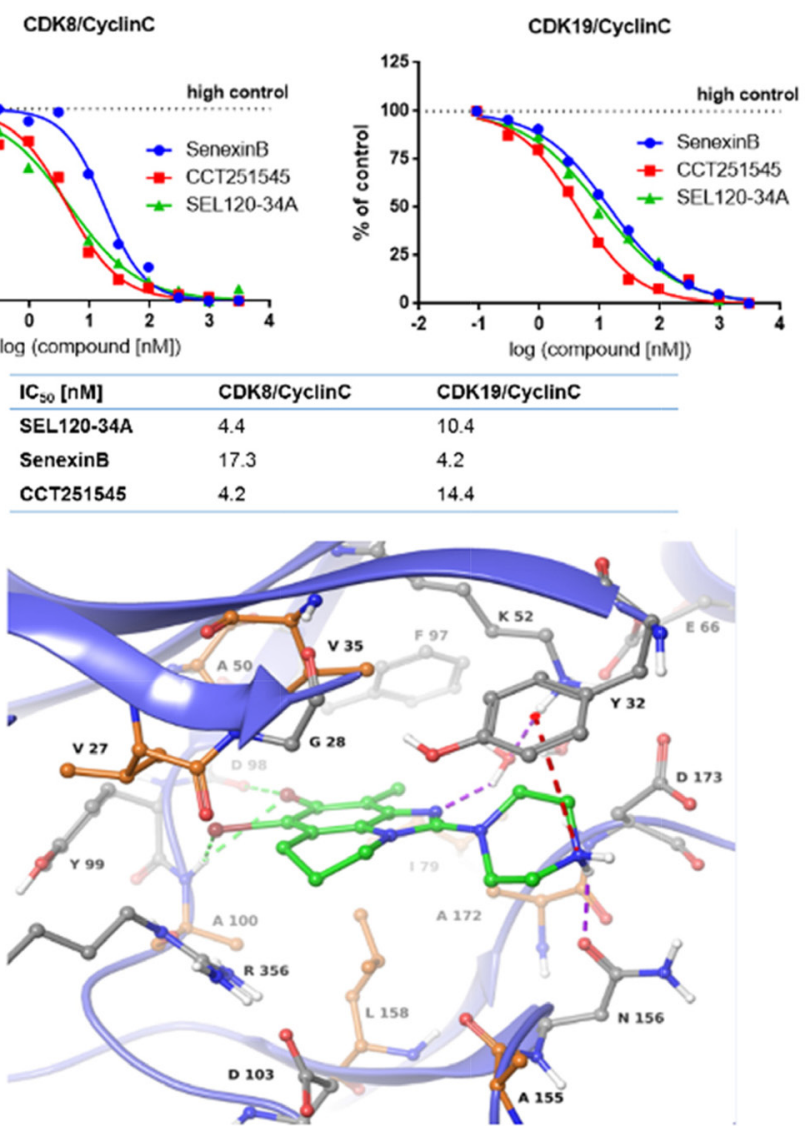

\begin{tabular}{llll}
\hline & \multicolumn{3}{l}{ \% remaining activity @1 $\mu$ M } \\
\hline SEL120-34A & repeat 1 & repeal 2 & Mean \\
CDK8/CycC & 3 & 1 & 2 \\
CDK9/CycT1 & 14 & 16 & 15 \\
CDK9/CycK & 45 & 38 & 41 \\
CDK2/CyCA2 & 57 & 62 & 60 \\
CDK2/CycE1 & 64 & 63 & 63 \\
CDK5/p35NCK & 72 & 68 & 70 \\
CDK1/CycA2 & 73 & 79 & 76 \\
CDK5/p25NCK & 82 & 78 & 80 \\
CDK7/CycH/MAT1 & 86 & 79 & 83 \\
CDK1/CycE1 & 90 & 86 & 88 \\
CDK1/CycB1 & 87 & 89 & 88 \\
CDK3/CycE1 & 97 & 82 & 89 \\
CDK4/CycD3 & 92 & 91 & 91 \\
CDK6/CycD1 & 91 & 95 & 93 \\
CDK4/CycD1 & 89 & 99 & 94 \\
\hline
\end{tabular}

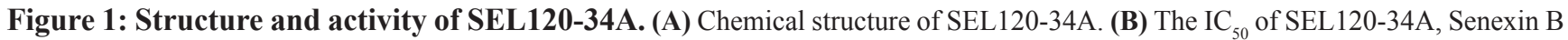
and CCT241545 determined by constructing a dose-response curve and examining inhibition of CDK8/CycC and CDK19/CycC activities at Km ATP concentrations. (C) \% remaining activities measured for members of the CDK family in the presence of $1 \mu \mathrm{M}$ SEL120-34A at Km ATP concentrations. (D) Active site of the crystal structure of human CDK8/CycC complexed with SEL120-34A. Protein residues and SEL120-34A are shown as Ball-and-Sticks. Protein carbon atoms are colored orange (aliphatic hydrophobic residues) or gray (other residues), while ligand carbon atoms are colored green. The following interactions are shown: $\mathrm{H}$ bond as purple dashed line, halogen bonding as green dashed line and cation- $\pi$ system interaction as red dashed line. 
expression under mitogen stimulation [8]. We challenged quiescent HCT-116 cells for 2 hours with $1 \mu \mathrm{M}$ SEL120$34 \mathrm{~A}$, followed by a time-course stimulation with FBS. SEL120-34A substantially repressed inducible expression of well-established IER genes, EGR1 and FOS (Figure 2D) [27]. Further assessment of IER genes showed a dose-dependent inhibition of EGR1 and FOS mRNA expression at $45 \mathrm{~min}$ of FBS stimulation (Figure 2E). In agreement with previous studies [8], these results indicate that pharmacological inhibition of CDK8 alters inducible IER gene expression.

\section{SEL120-34A inhibits IFN- responsive genes expression in vitro}

In order to determine whether SEL120-34A inhibits expression of well-established IFN-responsive genes, we measured expression of STAT1 and IRF9, since these were shown to be induced in CRC cell lines by both types of IFNs [28]. HCT-116 and Colo-205 were pretreated with SEL120-34A for 1 hour and then subjected to a IFNg or IFNa time-course. SEL120-34A significantly decreased IRF9 and STAT1 mRNA expression in at least one early
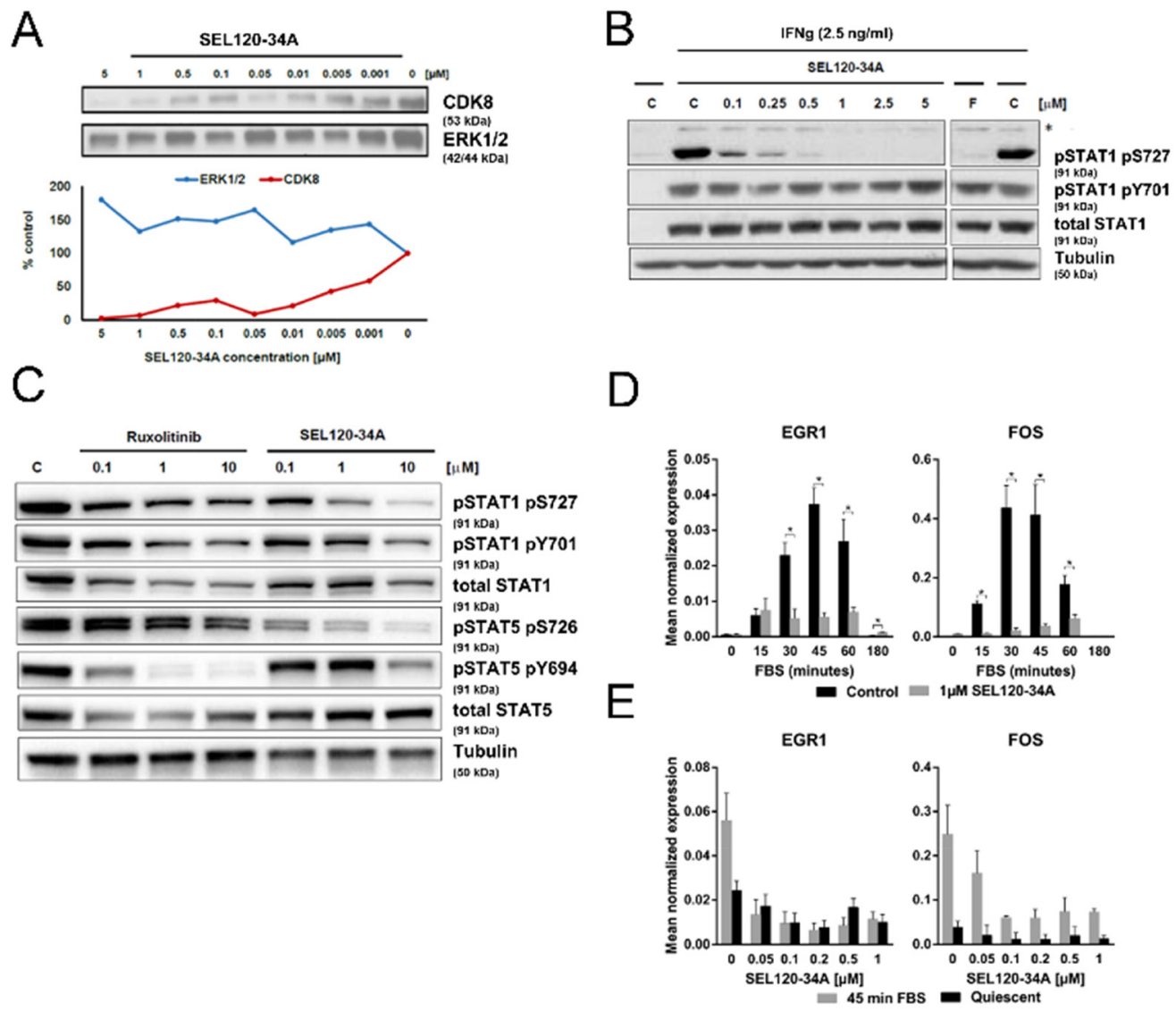

Figure 2: SEL120-34A inhibits phosphorylation of STAT1 S727 and STAT5 S726 and mitogen induced expression of immediate early response genes. (A) SEL120-34A competitively inhibits CDK8 binding to ATP -desthiobiothin probes (ActivX) in KG-1 AML cell lysate; ERK1/2 was used as a control. CDK8 and ERK1/2 proteins in precipitates were revealed by WB. (B) SEL120-34A inhibits IFN-dependent phosphorylation of STAT1 S727. HCT-116 cells stimulated with IFNg for $4 \mathrm{~h}$ were treated with increasing doses of SEL120-34A, Flavopiridol (F) or vehicle DMSO (C) to determine changes in the phosphorylation of STAT1 S727 and Y701, as measured by WB. (*) unspecific band. (C) SEL120-34A inhibits serine phosphorylation of STAT1 S727 and STAT5 S726, whereas Ruxolitinib inhibits tyrosine phosphorylation of STAT1 Y701 and STAT5 Y694 in JAK2 V617F cells. SET-2 cells were treated with Ruxolitinib, SEL120-34A or vehicle DMSO (C) for 24 hours and protein levels of pS727, pY701 STAT1 and pS726, pY694 STAT5 were measured by WB. (D) SEL120-34A inhibits serum- induced mRNA expression of immediate early response genes in a dose- dependent manner. HCT-116 cells were synchronized in $0.5 \%$ FBS medium for $24 \mathrm{~h}$, cells were pretreated for 120 minutes with $1 \mu \mathrm{M}$ SEL120-34A followed by activation with $10 \%$ FBS and subsequent RNA extraction, DNAse I treatment and qRT-PCR reaction. The results were normalized for RPLP0 mRNA (means \pm S.D., $\mathrm{n}=4$ ). Statistical analysis of differences between mRNA levels for control and SEL120-34A at the indicated time point was performed using t-tests. A p value of $\leq 0.05\left(^{*}\right)$ was considered significant. (E) HCT-116 cells were prepared as in panel $D$ and then challenged for 120 min with increasing doses of SEL120-34A, followed by the treatment with 10\% FBS 45 min. RNA was extracted, DNAse I digested and subjected to the qRT-PCR reaction. The results were normalized for RPLP0 mRNA (means \pm S.D., $\mathrm{n}=4$ ). 
$(0-3 \mathrm{~h})$ and late $(24 \mathrm{~h}-48 \mathrm{~h})$ time point in IFNg treated cells, whereas for IFNa, such a decrease was only clearly pronounced at the $48 \mathrm{~h}$ time point (Figure 3A). Next, we focused on $3 \mathrm{~h}$ and $48 \mathrm{~h}$ time points for IFNg and for IFNa, respectively. Treatment with increasing amounts of the drug demonstrated that the STAT1 transcript is modulated in a dose-dependent manner in both IFNs stimulations, while the same effect on IRF9 transcript became pronounced after a $48 \mathrm{~h}$ IFNa treatment (Figure 3B).

Collectively, these results suggest that SEL120-34A inhibits IFN-dependent gene expression, however the effects on these genes are modest and transient, indicating that CDK8 is not a major driver of STAT-dependent transcription in IFN-stimulated cancer cells in vitro.

\section{Transcriptome profiling reveals specific alterations in interferon- responsive genes after SEL120-34A treatment in vivo}

We studied STAT5 S726 and STAT1 S727 in Colo$205 \mathrm{CRC}$ xenograft tissues in mice, treated orally with increasing doses of SEL120-34A (Figure 4A). Nearly complete inhibitions of STAT1 S727 and STAT5 S726

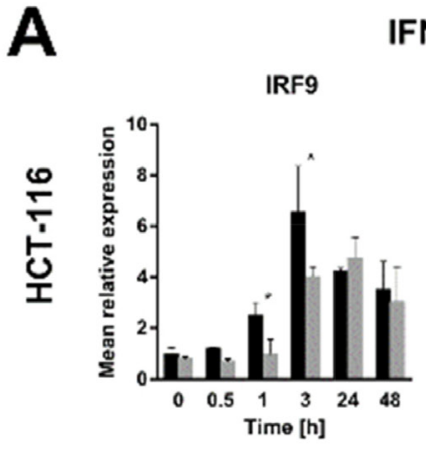

IF $\mathrm{Ng}$

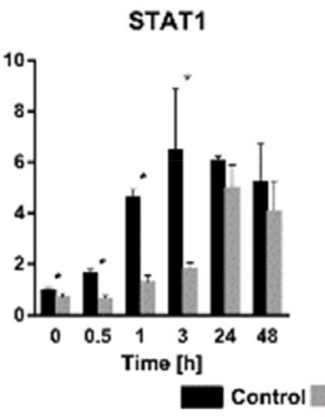

RF9
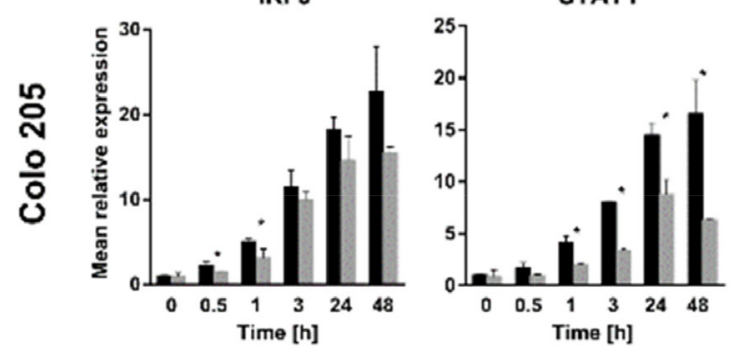

B

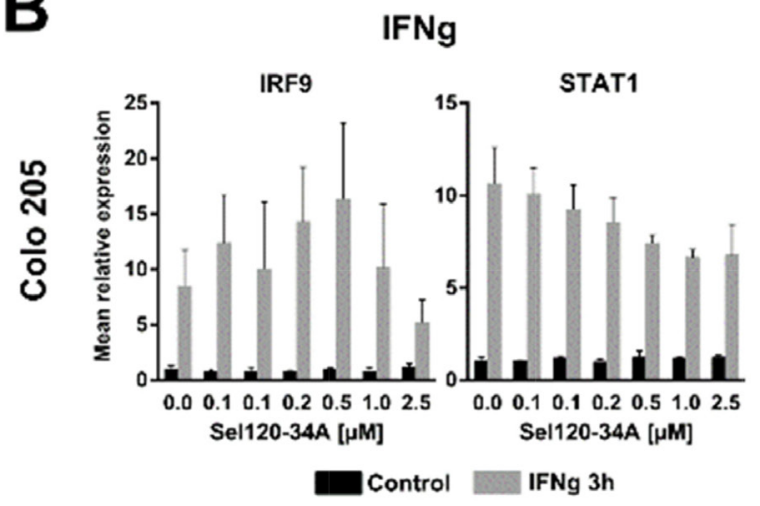

IFNa
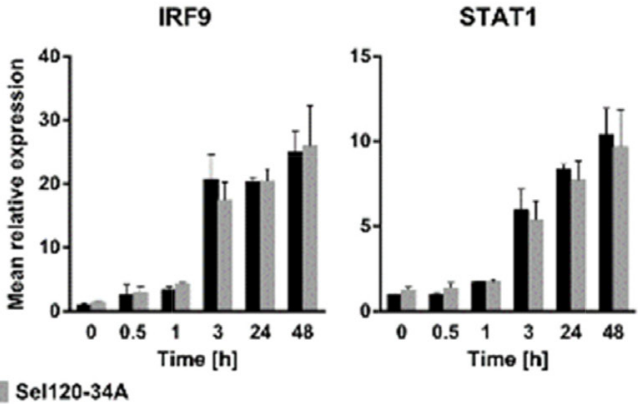

IRF9
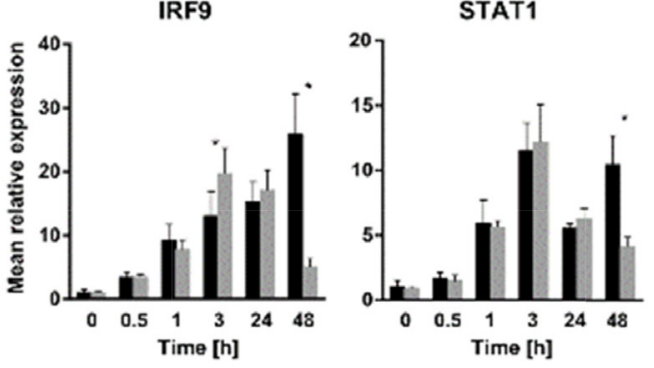

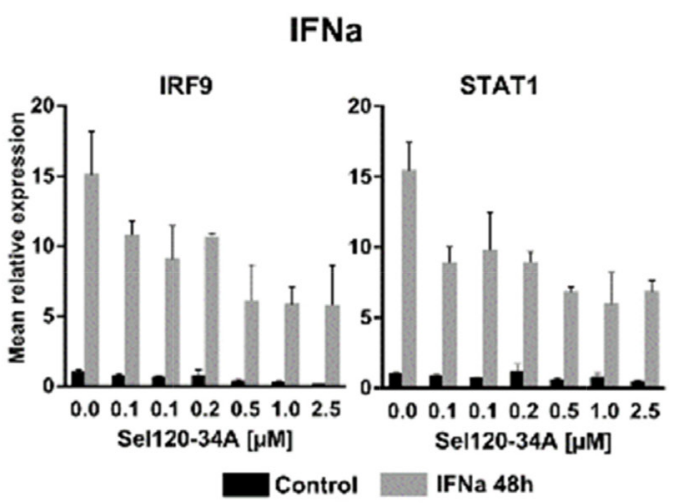

Figure 3: SEL120-34A inhibits interferon- induced genes expression in a dose dependent manner. (A) HCT-116 and Colo205 cells were made quiescent overnight by decreasing FBS in medium to $0.5 \%$ and then preincubated with $0.5 \mu \mathrm{M}$ SEL120-34A for $1 \mathrm{~h}$ followed by either IFNg $(5 \mathrm{ng} / \mathrm{mL})$ or IFNa $(250 \mathrm{units} / \mathrm{mL})$ stimulation in the presence of SEL120-34A . At the indicated time point, cells were harvested, RNA extracted and transcripts levels analyzed by the qRT-PCR reaction. The results were normalized for RPLP0 mRNA (means \pm S.D., $\mathrm{n}=3$ ). (B) Colo-205 cells were synchronized as in panel $A$ and then challenged with increasing doses of SEL120-34A for 1 $\mathrm{h}$ followed by either $3 \mathrm{~h} \mathrm{IFNg}(5 \mathrm{ng} / \mu \mathrm{l})$ or $48 \mathrm{~h} \mathrm{IFNa}(250 \mathrm{units} / \mathrm{ml})$ stimulation. At this time RNA was extracted, DNAse I digested and subjected to the qRT-PCR reaction. The results were normalized for RPLP0 mRNA (means \pm S.D., $n=3$ ). Differences between mRNA levels for control and SEL120-34A at the indicated time points were assessed by t-tests. A p value of $\leq 0.05(*)$ was considered significant. 
were observed at $60 \mathrm{mg} / \mathrm{kg}$, which resulted in a mean plasma concentration of the compound over $700 \mathrm{ng} / \mathrm{ml}$ at the 16 hour time point (Figure 4A).

It was plausible to expect that favorable pharmacodynamics of SEL120-34A could be sufficient to affect expression of CDK8 and CDK19- dependent genes in vivo. Whole transcriptome measurements were performed on Colo-205 xenograft tissues challenged with $30 \mathrm{mg} / \mathrm{kg}$ SEL120-34A at 4 and 16 hours after the last dose. This analysis revealed 678 differentiating $\left(p_{a d j}\right.$ $\leq 0.05$ ) probe sets in SEL120-34A treated Colo-205 (Supplementary Table 3). Manual inspection of the top differentially expressed genes (Figure 4B) indicated that the majority of genes repressed by the treatment were previously described as being STAT-regulated, including IRF9, IFI6, IFI27, TM4SF5, HEY1, OAS1 and ISG15; among many others [29]. The top $10 \%$ of differentially expressed probe sets (highest corrected $\mathrm{p}$-value $=0.008$ ) were then used for calculating their attribution to GO terms, which uncovered significant $\left(p_{a d j} \leq 0.05\right)$ overrepresentation of genes belonging to IFN signaling pathways (Supplementary Table 4). To confirm the expression changes from microarrays, we demonstrated inhibition of STAT1, ISG15 and IRF9 in xenografts challenged with increasing doses of SEL120-34A by RTqPCR. (Figure 4C). Reduced mRNA levels of STAT1 could also explain lower levels of STAT1 protein observed in treated tumors.

We next used GSEA [30] to investigate previously identified CDK8-dependent alterations, including SEassociated signatures [4] and curated gene sets (C2 v.5.1) from MSigDB. The highest enrichment scores were observed for IFN - target genes (NES 2.7) (Figure 4D) and for genes regulated by NUP98-HOXA9 - a frequent target of chromosomal rearrangements in leukemia (NES 3.1) [31-34]. Surprisingly, GSEA did not revealed significant enrichment of many signatures which were identified previously as being CDK8-dependent, including WNT/ $\beta$ -
A
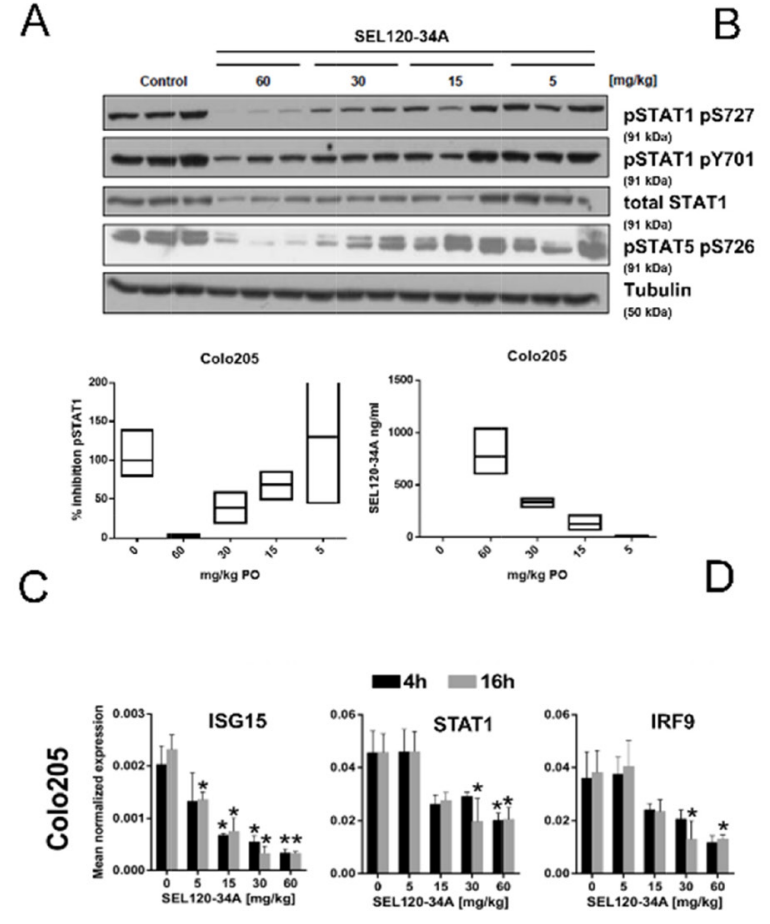

Control SEL120-34A
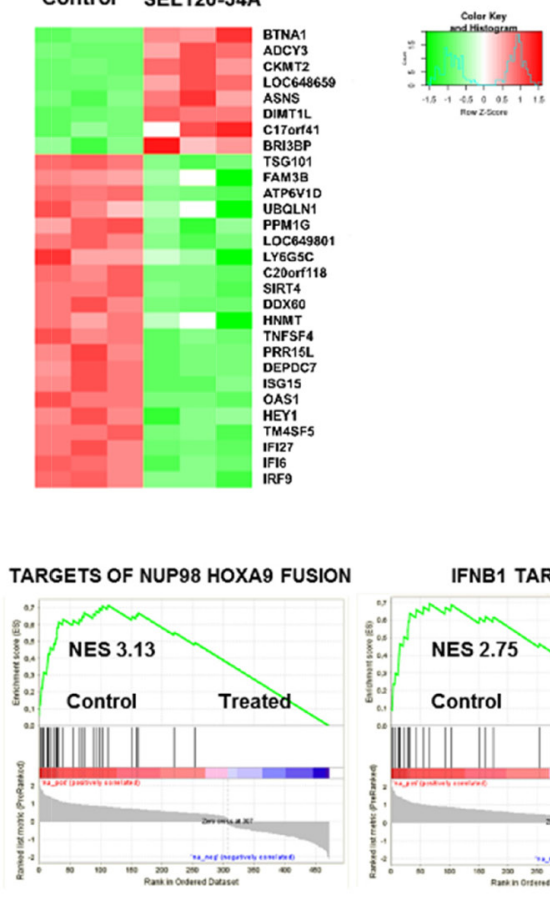

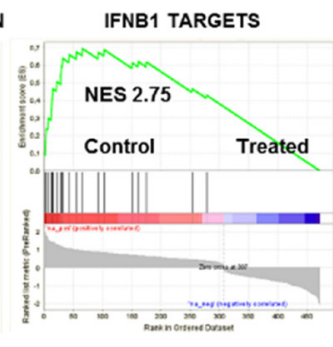

Figure 4: Xenografts transcriptome profiling reveals alteration in IFN- responsive genes upon SEL120-34A treatment in vivo. (A) Animals xenografted with Colo-205 tumors were dosed orally with 5, 15, 30 and $60 \mathrm{mg} / \mathrm{kg}$ BID for a total of 3 days and tumor samples were dissected 16 hours after the last compound dose. Water was used as a vehicle. Levels of phosphorylated STAT1 S727, Y701 and STAT5 S726 were measured by WB. Floating bars plots indicate relative inhibition of STAT1 S727, measured by densitometry of WB signals (left) and corresponding concentrations of SEL120-34A detected in plasma of treated animals, measured by LC-MS (right). Mean, min and max values are presented. (B) Heat map showing changes in expression levels of the top 30 differentially expressed genes (based on adj. p-values, Z-scores are shown) in Colo-205 tumors, after treatment with $30 \mathrm{mg} / \mathrm{kg}$ of SEL120-34A at 4h time point (C) Validation of microarray data by qRT-PCR for selected IFN-regulated genes. Animals were administered with 5, 15, 30 and $60 \mathrm{mg} / \mathrm{kg}$ BID for 3 days and Colo-205 tumor samples were collected at 4 and 16 hours after the last compound dose. Total RNA was extracted and subjected to qRT-PCR measurements. mRNA expressions of measured transcripts were normalized to RPLP0 expression $(n=3 ; \pm S D)$. Differences between mean cDNA levels for control and a given SEL120-34A dose at the indicated time point were assessed by t-tests. A p-value of $\leq 0.05(*)$ was considered significant. (D) GSEA running plots for expression changes in Colo-205 xenografts after SEL120-34A treatment. Normalized Enrichment Scores (NES) for the selected sets from the MSigDB C2 collection are shown - (Takeda Targets of NUP98-HOXA9 Fusion 3d Upand Hecker IFNB1 Targets). 
Catenin and SE-gene sets, identified previously in AML $[4,7]$ (Supplementary Table 5). Overall, these studies confirmed SEL120-34A as a specific and robust inhibitor of STATs-dependent gene expression in vivo.

Recently Clarke et al. also published microarray gene expression profiling of Colo-205 tumors treated with two distinct CDK8 inhibitors CCT251545 (described as CMPD1) and CMPD3 [35]. Despite comparable affinity to CDK8 in vitro and pharmacodynamics in vivo, only a $\sim 5 \%$ overlap was observed between affected genes (Figure 5A). Notably, the top upregulated gene - BTN1A1, was the same for all three compounds (Figure 5A, 5B). In contrast to CMPD1 and CMPD3, the majority of genes downregulated by SEL120-34A contained either STAT1 or HOXA binding elements (Figure 5B). Moreover GSEA had not identified significant enrichment in STATs and IFN - dependent genes among these regulated by CCT251545 (CMPD1) and CMPD3 in vivo (Figure 5B). Instead genes related to the activity of TLX, BMI, TNC and CTNBB1 were affected, which were absent in SEL120-34A treated tumors.

\section{Efficacy of pharmacological inhibition of CDK8 on cancer cells}

Our studies and those of other groups indicated moderate or low activity of known CDK8 inhibitors on CRC cell lines in vitro, therefore we have focused on leukemia cells which were found to be sensitive to CA [4]. Previous experiments indicated that SEL120-34A could repress phosphorylation of STAT5 which has been implicated in the maintenance of leukemia stem cells [36]. First, we determined that STAT5 S726 positive KG-1 AML cells were sensitive to prolonged treatment with SEL120-34A (Figure 6A, also compare with the Figure 7D), whereas S726 negative MOLM13 AML cells (Supplementary Figure 5A, compare with the Figure 7D) were resistant. Maximal inhibition of STAT5 S726 in KG-1 cells was achieved rapidly, after 1 hour of treatment (Figure 6B). Extended inhibition of STAT5 S726 by SEL120-34A was observed in the washout experiment, indicating long cellular residence time (Figure 6C). Continuous treatment with the compound in KG-1 cells showed sustained inhibition of STAT5 S726 and STAT1 S727 until day 6 and the hallmarks of apoptosis, such as cleaved Caspase-3, particularly at later time points (Figure 6D).

To determine whether pharmacological inhibition of CDK8 regulates viability of leukemia cells, we used SEL120-34A and two other CDK8 inhibitors, namely Senexin B [20], and CCT251545 [21]. All these compounds effectively bind to $\mathrm{CDK} 8 / \mathrm{CycC}$ (Supplementary Figure 1A) and could potently inhibit phosphorylation of STAT5 S726 and STAT1 S727 in KG-1 AML cell line (Figure 7A, 7B). At the same time RNAPII CTD S2 and MCL1, which are strongly dependent on the activity of CDK9 in leukemia cells, were not affected [37]. Overall, the lack of structural similarities, comparable affinity to CDK8 and selectivity of these probes enabled studies on CDK8-related processes in leukemia cells.

Broad profiling of SEL120-34A and Senexin B in a panel of AML cell lines revealed several sensitive $\left(\mathrm{GI}_{50}<1 \mu \mathrm{M}\right)$ - responder cell lines (SKNO-1, KG-1, HEL-60, MOLM-16, MV-4-11, OciAML-2, MOLM-6 and OciAML-3), consistent with the effective inhibition range of STAT1 S727 and STAT5 S726 (Figure 7C). Other cells were considered as non-responders when growth inhibition $\mathrm{GI}_{50}$ exceeded $1 \mu \mathrm{M}$. A differential sensitivity pattern was further corroborated by treatment with CCT251545 (Supplementary Figure 6). Surprisingly, all three CDK8 inhibitors were inactive on the MOLM-14 cell line, which was previously identified as sensitive to CA treatment by a mechanism involving deregulation of genes under the control of SE [4]. We excluded misidentification of this and all other cell lines by the short tandem repeat analysis.

\section{Sensitivity of AML cell lines to the treatment with CDK8 inhibitors correlates with the presence of STAT5 S726 and STAT1 S727}

Previous studies have demonstrated that cells sensitive to CA treatment responded by deregulation of SE-dependent genes, however discriminating markers which could predict sensitivity to CDK8 inhibitors have not been identified [4]. Our studies confirmed differential activity of selective CDK8 inhibitors on leukemia cells in vitro. Thus, we divided AML cell lines into two classes based on their sensitivity to CDK8 inhibitor treatment (responders and non-responders) and then analyzed levels of phosphorylated STAT1 and STAT5 in these cells (Figure 7D). Clearly, a group of responder AML cell lines was characterized by significantly higher levels of STAT5 S726 (Figure 7E) and STAT1 S727 (Figure 7F), whereas cell lines resistant to CDK8 inhibitors were largely negative for these phosphorylation marks.

Our next objective was to identify sets of discriminating genes that could be used for characterizing and predicting response to CDK8 inhibitors. We identified differentially expressed genes between responder and nonresponder AML cell lines (Figure 8A) using expression data from the Cancer Cell Line Encyclopedia (CCLE) [38] and ranked them using p-values from multiple statistical models for evidence of differential expression (DEDS) [39]. Clustering of genes with the highest DEDS scores, classified analyzed AML cell lines into 3 groups: nonresponder cells with high expression of genes indicating myeloid commitment such as MPO, MNDA and ELANE and two distinct responder classes (Figure 8B). The first responder class was characterized by the high expression 


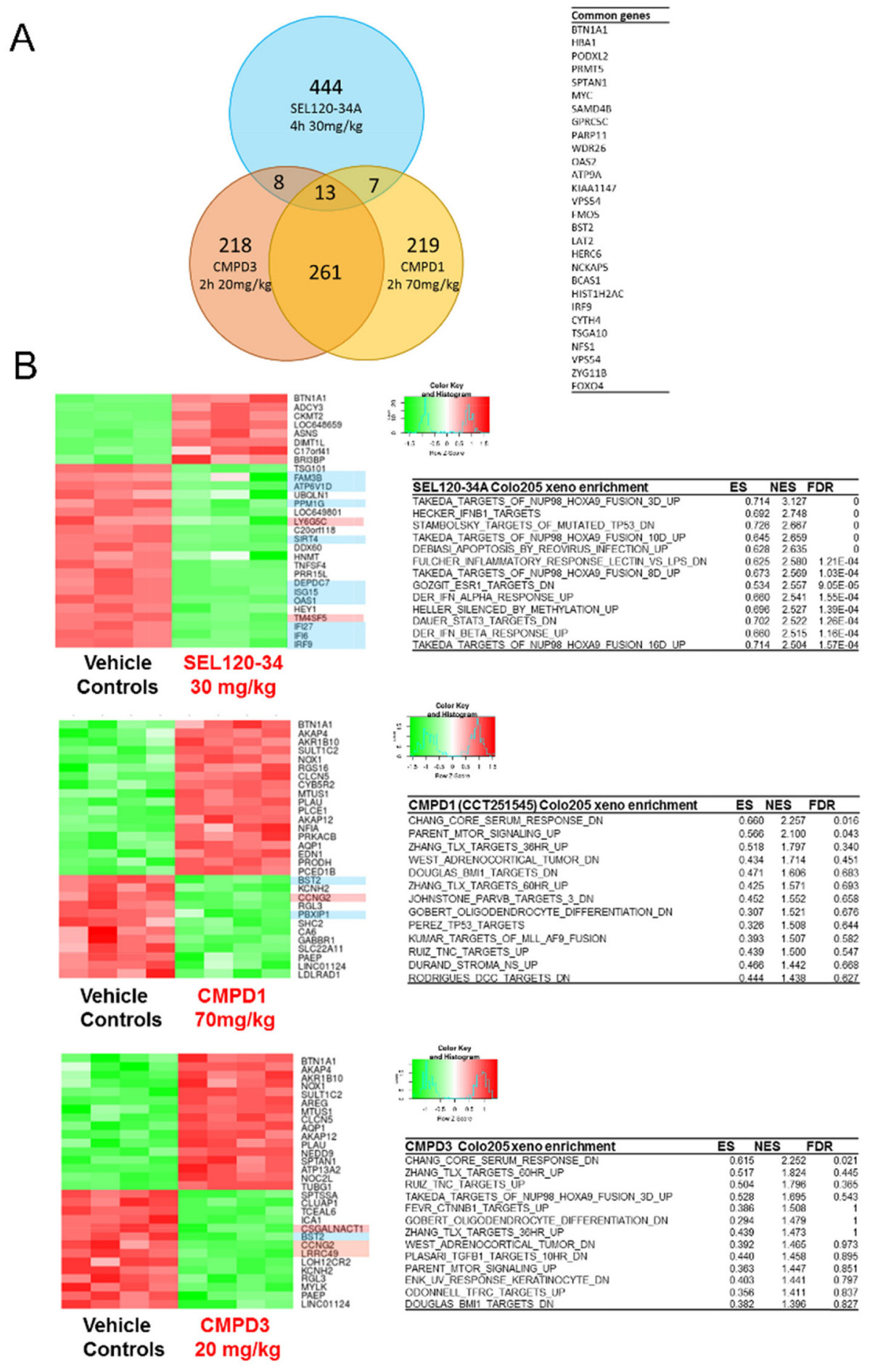

Figure 5: Transcriptional profiling of Colo-205 xenografted tumors revealed differences between SEL120-34A and two other CDK8 inhibitors - CCT251545 (CMPD1) and CMPD3. (A) Venn diagram showing overlap in significantly regulated genes by SEL120-34A 30mg/kg, CCT251545 (CMPD1) 70 $\mathrm{mg} / \mathrm{kg}$ and CMPD3 20mg/kg (Clarke et al.) based on adj. p-values. A list of common genes between SEL120-34A and both CMPD1 and CMPD3 is shown in tabular form. (B) Heatmaps presenting Z-scores for the top list of genes regulated in Colo-205 tumors by the treatment with SEL120-34A, CCT251545 (CMPD1) and CMPD3 (Clarke et al.). Gene names with a blue background indicate presence of STAT binding sites and red indicate HOXA binding sites in the promoters as analyzed by SABiosciences' database DECODE. Tables present GSEA analysis (MSigDB C2 collection) for expression changes in Colo-205 xenografts after treatments with indicated compounds, Enrichment Scores (ES), Normalized Enrichment Scores (NES) and False Discovery Rates (FDR) are shown. 
of marker genes for hematopoietic progenitor and stem cells, such as HOXB2 and ITGA2B (CD41) and IL1B [40, 41]. RT-qPCR analysis of discriminating genes confirmed elevated expression of MNDA in non-responder cells with low STAT5 S726 levels, whereas IL1B was highly elevated in the first cluster of responder cells with high STAT5 S726 levels (Figure 8D). CD34, which is well established marker of hematopoietic and leukemia stem cells [42-44], was detectable only in the first responder cluster.

GSEA using SE-associated signatures [4] and curated gene sets (C2 v.5.1) from MSigDB confirmed high enrichment of genes associated with hematopoietic stem cells (NES 3.4) and NUP98-HOXA9-target genes (NES 2.9) in responder cells, relative to non-responders AML cells (Figure 8C and Supplementary Table 6). In contrast, a high enrichment of genes downregulated in leukemic stem cells was observed in non-responder cells (NES -3.2). Interestingly, non-responder cells were also characterized by a high enrichment of genes classified by Pelish et al. as genes with high levels of histone acetylation and modulated by CA in MOLM-14 cells (Figure 8C and Supplementary Table 7).

\section{Efficacy of SEL120-34A in AML xenograft models}

Next, we assessed in vivo activity of SEL120-34A in xenografted KG-1 and MV4-11 AML tumors grown in SCID mice models. SEL120-34A treatment resulted in completely arrested growth of $\mathrm{KG}$-1-derived tumors and a reduced volume of MV4-11 tumors, without appreciable loss in body weight (Figure 9A and 9B).

High levels of STAT5 S726 in analyzed KG-1 and MV4-11 tumor tissues allowed for pharmacodynamic measurement of target engagement, whereas MOLM13 cells were negative for STAT5 $\mathrm{S} 726$ also in vivo (Supplementary Figure 5B). We observed dose-dependent inhibition of STAT5 S726 after oral administration of the compound once a day in KG-1, whereas STAT1 S726 was unaffected (Figure 8C). Analysis of MV4-11 indicated that in addition to STAT5 S726, total STAT5 levels were also repressed (Figure 8D). More detailed analysis of MV4-11 tumors indicted repression of oncogenic MCL-1 without any appreciable reduction in phosphorylation levels of RNAPII CTD S2 and clear signs of apoptosis shown by cleaved PARP. Finally, subchronic 14 days SEL120-34A
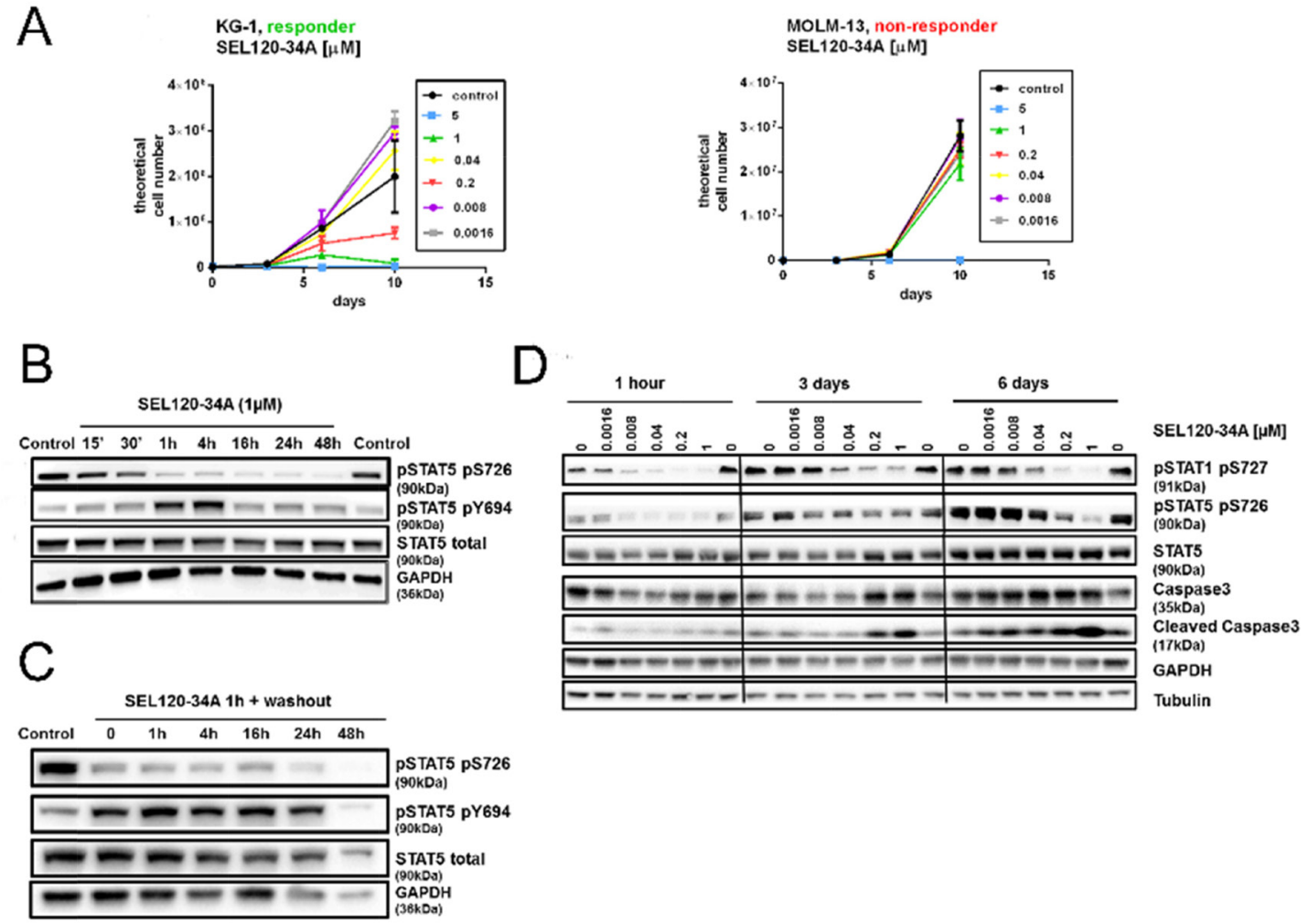

Figure 6: Efficacy of SEL120-34A in responder AML cells lines coincides with the inhibition of STAT5 S726. (A) Growth curves of responder KG-1 cell line and non-responder MOLM-13 cell line treated with increasing concentrations of SEL120-34A (B) Timedependent effects of $1 \mu \mathrm{M}$ SEL120-34A in KG-1 cells. Levels of STAT5 and phosphorylated STAT5 S726 and Y694 were measured by WB. (C) STAT5 S726 inhibition after the wash-out, following $1 \mathrm{~h}$ treatment with $1 \mu \mathrm{M}$ SEL120-34A. (D) Effects of prolonged SEL120-34A exposures in KG-1 cells. KG-1 were treated with SEL120-34A for $1 \mathrm{~h}, 3$ days and 6 days and levels of total STAT5, STAT5 S726, STAT1 S727, Caspase 3 and Cleaved Caspase 3 were measured by WB. 
treatment was not associated with significant alterations in the peripheral blood of healthy immunocompetent CD-1 mice (Supplementary Table 8).

\section{DISCUSSION}

SEL120-34A is a novel CDK8 inhibitor with high potency, selectivity and favorable pharmacokinetics and pharmacodynamics. The crystal structure of CDK8/CycC with SEL120-34 gives insight into the binding mode

of SEL120-34 and reveals key interaction sites in the protein. It occupies the ATP- binding site and also forms contacts with the front pocket including Arg 356 which is a unique structural feature in the CDK family. Comparing SEL120-34A binding mode with other type I CDK8 inhibitors, reveals that it is the only inhibitor with a high inhibitory potency in the absence of extended decoration protruding from the pocket. The favourable affinity of SEL120-34A to CDK8 can be explained by the high shape complementarity of the molecule with the pocket
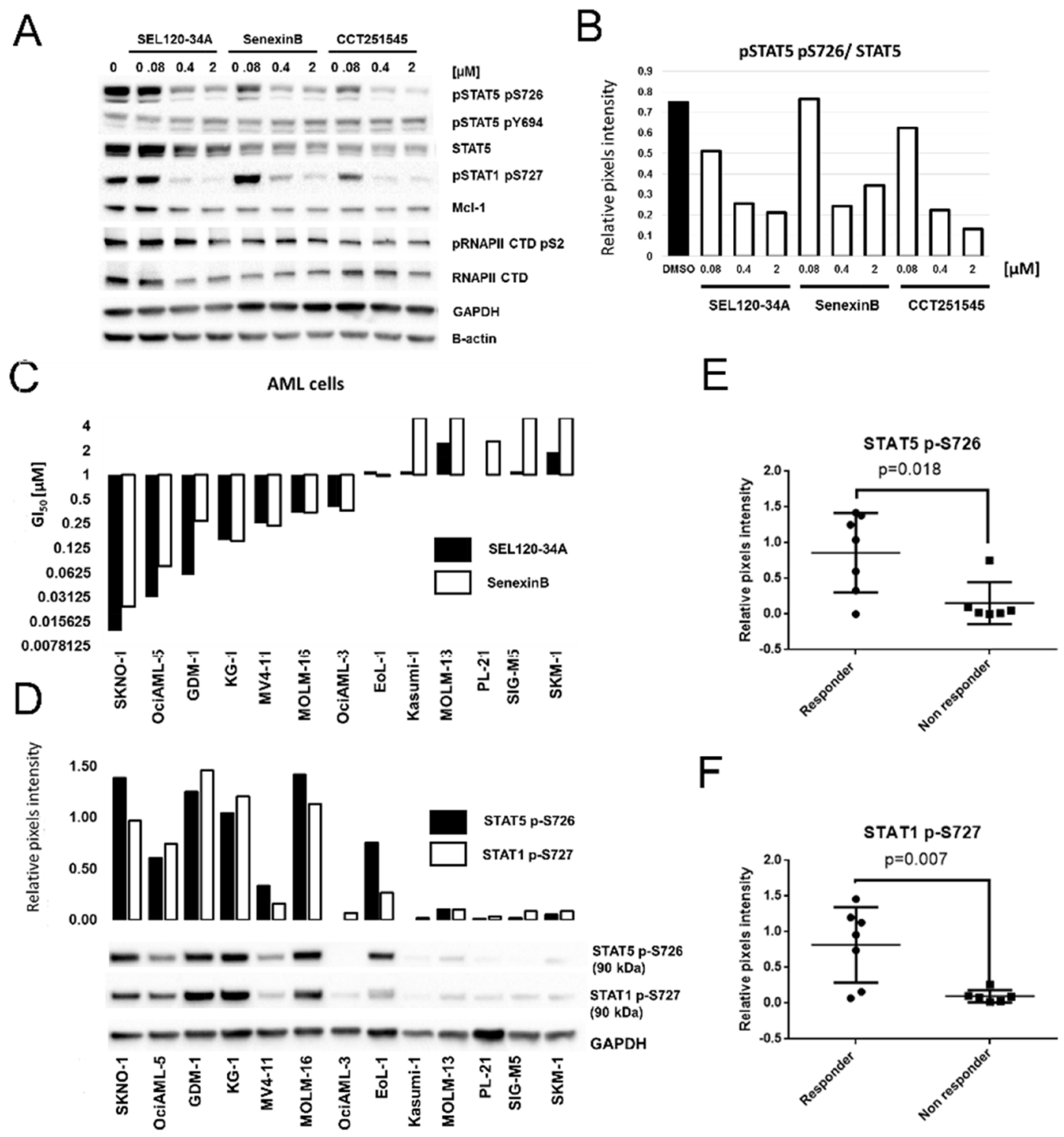

Figure 7: Treatment with CDK8 inhibitors results in differential activity on AML cell lines positive for phosphorylated STAT5 S726 and STAT1 S727. (A) KG-1 cells were treated for $24 \mathrm{~h}$ with SEL120-34A, Senexin B and CCT251545 and levels of total STAT5, phosphorylated STAT5 S726, Y694, phosphorylated STAT1 S727, MCL-1, total RNAPII CTD and phosphorylated RNAPII CTD S2 were measured by WB. (B) Densitometry showing relative repression of phosphorylated STAT5 S726 (normalized to total STAT5) by CDK8 inhibitors from panel A. (C) Effects of SEL120-34A and Senexin B on the growth of indicated AML cell lines, measured by extended viability tests. Mean $\mathrm{GI}_{50}$ (day 10) is shown and plotted on the graph $(\mathrm{n}=3)$. (D) Levels of phosphorylated STAT5 S726 and STAT1 S726 in AML cells from the panel $C$ were measured by WB. Densitometry for STAT5 S726 and STAT1 S726 signals is shown and plotted on the graph. Cell lines from the panel $D$ were divided into two classes based on the sensitivity to CDK8 inhibitors treatment (responders $\mathrm{GI}_{50}<1$ $\mu \mathrm{M}$ and non-responder $\mathrm{GI}_{50}>1 \mu \mathrm{M}$ ), mean levels of STAT5 S726 (E) or STAT1 S727 (F) in selected cell lines measured by densitometry were presented on scatter plots. Differences between responder and non-responder were assessed by t-tests ( $\mathrm{p}$ value is shown). 


\begin{tabular}{|c|c|c|c|}
\hline & Name & DEDS & Fc \\
\hline 1 & PRTN3 & 0.00 & .6 .27 \\
\hline 2 & MPO & 0.00 & .5 .71 \\
\hline 3 & ELANE & 0.00 & -5.13 \\
\hline 4 & CSTA & 0.14 & .4 .77 \\
\hline 5 & ANKRD22 & 0.14 & -3.22 \\
\hline 6 & AZU1 & 0.14 & .4 .41 \\
\hline 7 & SERPINB6 & 0.14 & 3.08 \\
\hline 8 & ST3GAL6 & 0.18 & -3.26 \\
\hline 9 & ITGA2B & 0.18 & 3.38 \\
\hline 10 & HPGDS & 0.18 & 3.59 \\
\hline 11 & IL1B & 0.18 & 3.16 \\
\hline 12 & MNDA & 0.20 & -3.98 \\
\hline 13 & VSTM1 & 0.20 & 3.46 \\
\hline 14 & AlM1 & 0.20 & -3.42 \\
\hline 15 & FCER1A & 0.20 & 2.94 \\
\hline 16 & $S 100 A 8$ & 0.20 & -3.70 \\
\hline 17 & KIAA0125 & 0.20 & 3.39 \\
\hline 18 & ECRP & 0.20 & .2 .90 \\
\hline 19 & GNG11 & 0.20 & 3.13 \\
\hline 20 & HOXB2 & 0.20 & 2.88 \\
\hline
\end{tabular}

C

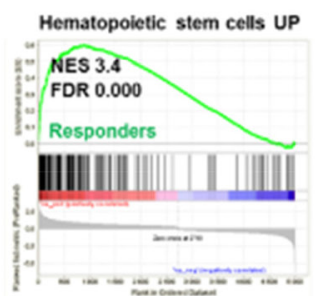

SE-rogulated genes (K27Ac CA)

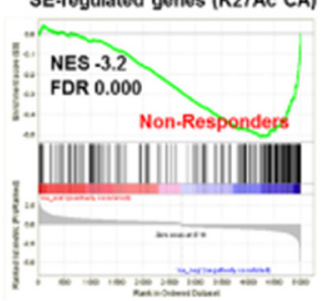

B
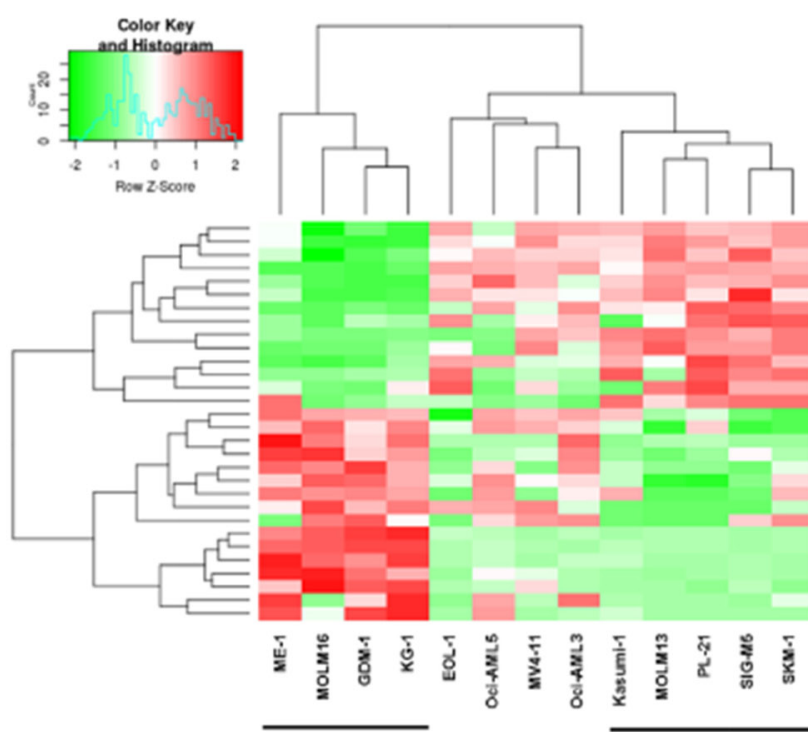

Cluster \#1

Responder

Cluster \#3

Non-responder

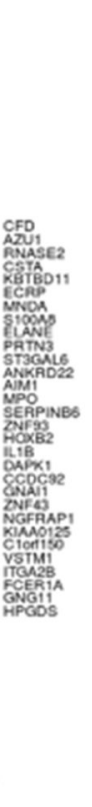

D
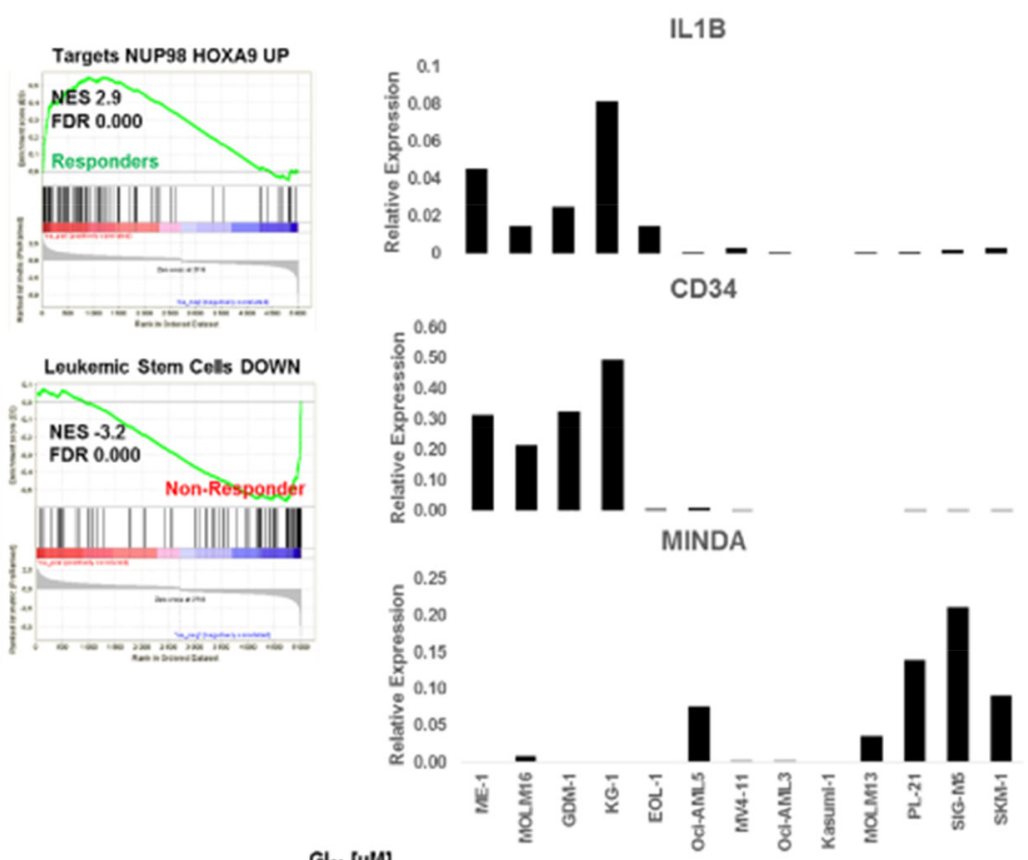

$\mathrm{Gl}_{60}[\mu / M]$

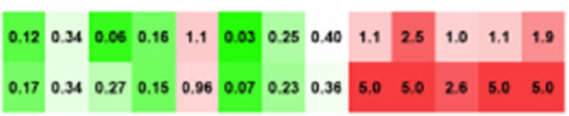

Figure 8: Identifying discriminating genes that can be used for predicting response to CDK8 inhibitors. (A) Alist of the top 20 genes discriminating between CDK8 inhibitors responder and non-responder AML cells, ranked by DEDS scores, fold changes are shown (Fc). (B) Heat map showing results of clustering (Z-scores) for top discriminating genes between responder and non-responder AML cells. (C) GSEA for two classes: responder and non-responder cells. Running plots for sets (MSigDB C2 collection) with the most significant enrichment scores (NES) in both responder and non-responder classes are shown. (D) CD34, IL1B and MNDA mRNA expression levels were analyzed in AML cell lines from the panel $B$ by qRT-PCR. Relative expression levels normalized to GAPDH are shown (representative biological repeat $n=2$, mean values from technical repeats $n=3$ ). Heat map presenting $\mathrm{GI}_{50}$ values for tested $A M L$ cells lines treated with SEL120-34A and Senexin B in extended viability assays is presented below for a comparison with gene expression data. 
and several types of formed interactions, including three halogen bonds with the hinge and an ionic interaction with Asp 173.

Functional studies indicated that CDK8 could act as an oncogene in $\mathrm{CRC}$ through induction of $\mathrm{WNT} / \beta$-Catenin signaling [7]. SEL120-34A treatment, in contrast to some other CDK8 inhibitors $[14,21]$ shows high specificity on STATs genes in vivo, without significant interference with other pathways such as WNT/ $\beta$-Catenin signaling. At the time of writing this manuscript, Clarke et al. published results including transcriptional characterization of Colo-205 tumors treated with two chemically related CDK8 inhibitors [35]. It has been surprising to observe largely distinct effects of these compounds in vivo when compared with SEL120-34A. Despite robust inhibition of STAT1 S727 by these compounds, only minor effects on STAT-dependent genes could be observed. In contrast many of the genes which were significantly affected could contribute to the reported toxicity profile.

Specific effects of SEL120-34A on the STAT pathway could be anticipated based on the robust inhibition of phosphorylated STATs. It was astonishing to observe that transcriptional profiling demonstrated such a dominant effect on the IFN-responsive genes in vivo, which are generally considered to be a tumorsuppressive pathway in solid tumors [45]. More recently, this simplified view on the role of STAT1 has been challenged by reports indicating that STAT1 up-regulation causes activation of genes which are associated with increased resistance of tumor cells to
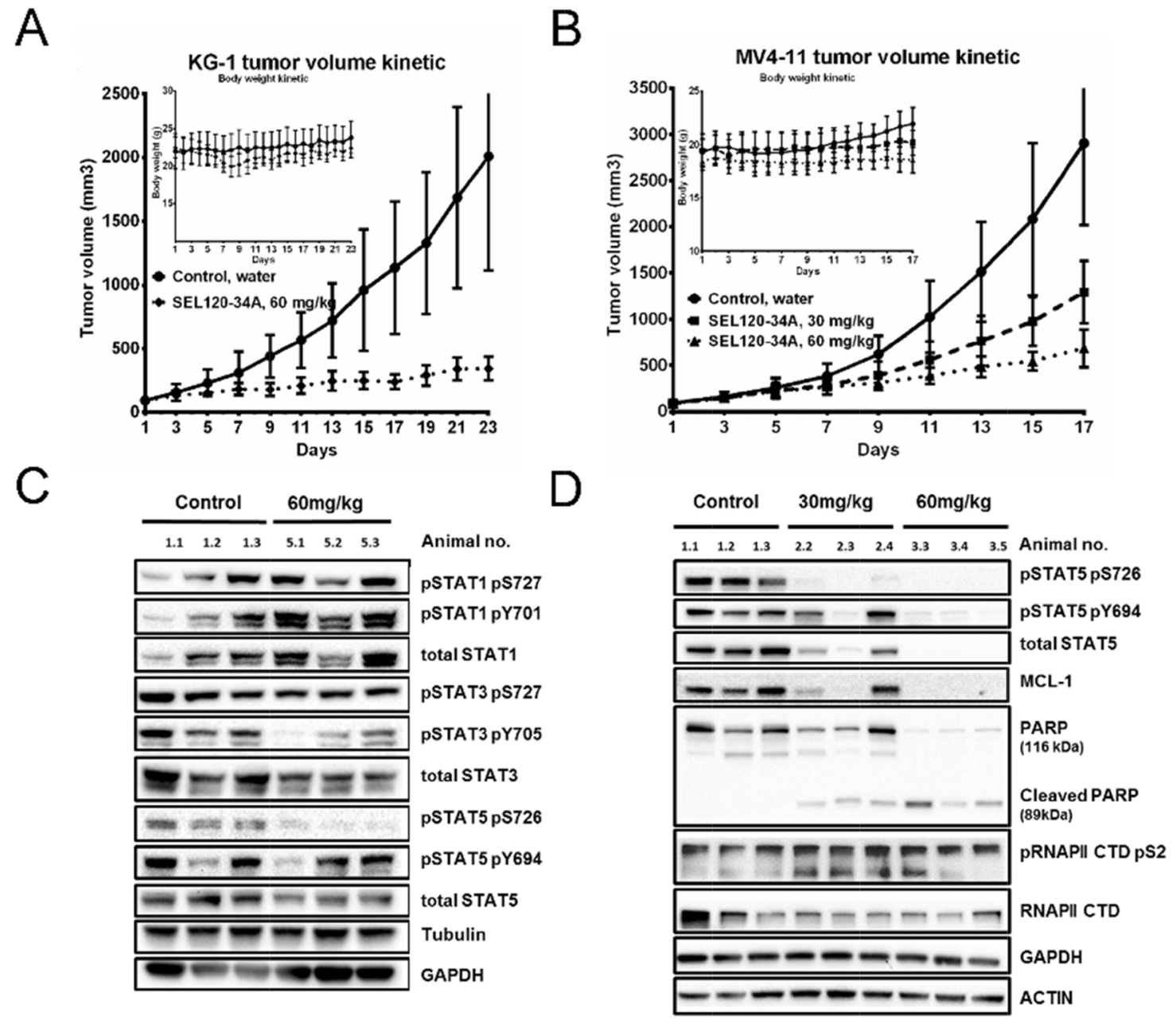

Figure 9: SEL120-34A inhibits growth of AML tumors in a dose- dependent manner. (A) Volume kinetic of KG-1 tumors and (B) MV4-11 tumors grown subcutaneously in SCID mice, treated orally with vehicle (water) or indicated doses of SEL120-34A once every day. Changes in animals' body weights are shown in the inset; $\mathrm{n}=8$, SD is shown. (C) Levels of total STAT1, STAT3 and STAT5 and phosphorylated STAT1 S726, Y701, STAT3 S727, Y705, STAT5 726, Y694 were analyzed in KG-1 tumors from control (vehicle) and SEL120-34A treated animals at day 23. (D) Levels of total on STAT5 and phosphorylated STAT5 S726, Y694, MCL-1, PARP and Cleaved PARP, total RNAPII and phosphorylated RNAPII CTD S2 were analyzed in MV4-11 tumors from control (vehicle) and SEL120-34A treated animals at day 17. 
genotoxic stress and tumor growth in breast cancer [46, 47]. Modulation of response to genotoxic stress has been postulated as one of the therapeutically relevant mechanisms of action for CDK8 inhibitors, which may increase efficacy of cancer chemotherapy [10]. High expression of STAT-dependent genes, many of which are regulated by SEL120-34A in vivo, is one of the features of the consensus molecular subtype CMS1 for colorectal cancer, characterized by substantial infiltration of immune cells and a DNA-damage response [48]. The exact role of CDK8 in the process of immune-evasion of cancer cells is still unknown, however it may be partially related to the STAT1 S727 dependent repression of NKcells cytotoxicity [49]. SEL120-34A, does not affect normal hematopoiesis and could thus be considered for further immunomodulatory studies.

Interestingly, GSEA for SEL120-34A-related transcriptional changes in vivo, showed high enrichment of genes involved in the leukemic transformation of human hematopoietic cells by NUP98-HOXA9 chimeric protein resulting from $\mathrm{t}(7 ; 11)(\mathrm{p} 15 ; \mathrm{p} 15)$ chromosomal translocation. This genetic rearrangement is the prototype of several NUP98 fusions that occur in AML, where STAT5 rather than STAT1 transcription appears to play a dominant role. Constitutive activation of STAT5 has been observed in the vast majority of AML cases, and repression of STAT5 impairs long-term maintenance of leukemic stem/progenitor cells [50-53]. Recently, pharmacological inhibition of CDK8 has been shown to suppress proliferation in a subset of AML cell lines [4]. Our results recapitulate some of these findings and validate SEL120-34A as a strong inhibitor of proliferation in AML cell lines, both in vitro and in vivo. The complex nature of these effects is evident given the significant differences in cell lines sensitivity between CA and the three other type I CDK8 inhibitors used in this study. It is intriguing that SEL120-34A and two other inhibitors lack activity on cells previously characterized by the restrained activation of SEassociated genes (such as MOLM-14).

Our results provide, for the first time, evidence for phosphorylated STAT5 and STAT1 as markers for selecting AML cell lines sensitive to treatment with CDK8 inhibitors. At the same time we propose STAT5 S727 as a major pharmacodynamical marker in AML. Activity of STAT5 is often associated with leukemia stem cells phenotype and therefore it has not been surprising in this context to observe that several sensitive AML cells were CD34 positive. Transcriptional profiling of these cells identified gene expression programs associated with stem cells phenotype, whereas resistant cells expressed genes indicating lineage commitment.

Further work is clearly needed in order to establish whether predictive biomarkers for identifying clear responders to CDK8 inhibitors could be applicable in the clinical context.

\section{MATERIALS AND METHODS}

\section{Chemicals and stock solutions}

Reference compounds were synthesized accordingly to procedures described in the patent: Senexin B (Senex Biotechnology Inc.) WO2014/134169A1, whilst synthesis of CCT241545 has already been described [14].

\section{CDK8 and CDK19 kinase assay}

A radiometric protein kinase assay (PanQinase ${ }^{\circledR}$ Activity Assay, ProQinase) was used for measuring activities of $\mathrm{CDK} 8 / \mathrm{CycC}$ and $\mathrm{CDK} 19 / \mathrm{CycC}$ protein kinases. The CDK8 Eu kinase binding assay (Life Technologies) for $\mathrm{CDK} 8 / \mathrm{CycC}$ was performed according to the manufacturer's instructions.

\section{Kinase capture experiments using ATP-desthiobiothin}

Kinase capture experiments were performed using the Kinase Enrichment Kit (Pierce) according to manufacturer's instructions, Briefly, kinases were captured for 10 min with $10 \mu \mathrm{M}$ ATP desthiobiothin probe in lysis buffer/ $4 \mathrm{M}$ urea. Captured kinases were pulled down with agarose and analyzed by Western blot.

\section{X-Ray crystallography}

Protein expression and purification of the corresponding CDK8 (Hs1-403)/ CycC (Hs1-283) constructs were performed according to previously published protocols [54]. Protein crystals were obtained within the hanging drop setup as described in the literature [54]. Data set collection and processing is described in the supplementary materials and methods.

\section{Cell cultures}

The full list of cell lines used and growth conditions are provided in the supplementary methods. Cell line genotypes were confirmed by multiplex short tandem repeat amplification (GenMed, Poznań, Poland). In some experiments cells were treated with human type I interferon $\alpha / \beta$ at $250 \mathrm{IU} / \mathrm{ml}$ (IFNa) (Sigma) or type II interferon $\gamma$ (IFNg) at $2.5 \mathrm{ng} / \mathrm{ml}$ (BioLegend), as indicated in figure legends.

\section{Serum, IFNa and IFNg treatment for gene expression measurements}

HCT-116 and Colo-205 cells were seeded onto 6 -well plates at $2.5 \times 10^{5} /$ well. On the following day, cells were synchronized for $24 \mathrm{~h}$ by $0.5 \%$ FBS starvation, pretreated with $0.1 \%$ DMSO or SEL120-34A at the indicated concentration for $1 \mathrm{~h}$ and then supplemented 
with either $10 \% \mathrm{FBS}$, IFNg or IFNa in the presence of the inhibitor. Cells were centrifuged at $1300 \mathrm{rpm}$ for $5 \mathrm{~min}$ at $4^{\circ} \mathrm{C}$, washed once with $1 \mathrm{ml}$ of ice-cold PBS and stored at $-80^{\circ} \mathrm{C}$.

\section{Extended cytotoxicity tests}

Cells grown in suspension were plated onto 96well culture dishes in triplicate at 20000 cells per well in $200 \mu \mathrm{l}$ of their culture medium, except Kasumi-1 cells, which were plated at $60000 /$ well. Cells were incubated in the presence of vehicle, $1 \mu \mathrm{M}$ docetaxel (positive control, Santa Cruz Biotechnology) or 6 serially - diluted concentrations of tested compound. The compound effect was determined by AlamarBlue measurement. On days $3,6-7$ and 10 , an equal volume from all wells was also split-back with fresh media supplemented with tested compound, resulting in a cell density for the vehicle well that matched the initial seeding density. For days 6-7, 9-10 and $13-14$, the theoretical cell number represents the splitadjusted cell number plotted versus concentration and time. $\mathrm{GI}_{50}$ and $\mathrm{IC}_{50}$ values were interpolated from doseresponse curves for each timepoint fitted by GraphPad Prism 6.

\section{Xenograft experiments}

All animals were handled in strict accordance with good animal practice as defined by the relevant national and local animal welfare bodies. Animals, SCID/beige C.B17 female mice were provided by Harlan Laboratories or Charles River Laboratories, and were maintained in pathogen free conditions.

Mice were inoculated subcutaneously (sc) above the groin on the right hind limb with $4 \times 10^{6} \mathrm{MV}-4-11$ or KG-1 leukemia cells, $5 \times 10^{6}$ Colo-205 CRC cells in a $0.1 \mathrm{ml}$ mixture $(3: 1, \mathrm{v}: \mathrm{v})$ of PBS and Matrigel (BD Biosciences, Growth Factor Reduced, Phenol Redfree; \#356231). Once tumors reached a mean volume of approximately $100 \mathrm{~mm}^{3}$ for tumor growth assessment or $250 \mathrm{~mm}^{3}$ for pharmacodynamics assessment, the mice were then randomly divided into uniform groups followed by compound or vehicle administration. Prior to use, the test compound was dissolved freshly in water at indicated doses and administered per os (PO) using cannula in a volume of $10 \mu \mathrm{l}$ per $1 \mathrm{~g}$ of body weight. After the last administration, mice were subjected to anesthesia for blood collection, and sacrificed for tumor collection.

\section{Toxicology assessment}

To evaluate toxicity of the SEL120-34A compound, a 14-days toxicology study was run in CD-1 female mice. The day before the first administration of vehicle (BID, PO) or test compound, mice were weighed and randomized into uniform groups ( 5 mice per group). Prior to use, the test compound was dissolved freshly in water and administered PO at indicated doses in a volume of 10 $\mu l$ per $1 \mathrm{~g}$ of body weight. Body weight and the general condition of the animals were monitored daily. When the study finished on Day 15, mice were subjected to anesthesia, and blood was collected into tubes containing $\mathrm{K}_{2}$ EDTA for analysis of hematology parameters (ABC Vet Animal Blood Counter).

\section{Microarray analysis and GSEA}

Colo-205 tumours were used for the whole transcriptome analysis. The average signal from the HumanHT-12 v4 Expression BeadChips (AROS Applied Biotechnology, Aarhus N, Denmark) was quantile normalized with no background correction. All computations were performed as previously described [55]. Differentially expressed probe sets were identified using a t-test (Welch variant), followed by the BenjaminiHochberg $p$-value correction for multiple hypotheses testing. Adjusted $p$-values $\left(p_{a d j}\right) \leq 0.05$ were considered significant. The $\log _{2}$ fold change values of SEL12034A-treated samples versus control samples were used for the ranking of genes and as an input for the Gene Set Enrichment Analysis (GSEA). The GSEA version 2.2.2 [30] was carried out using the GSEA preranked module. Signatures included curated gene sets (C2 v.5.1) downloaded from MSigDB as well as published data sets [4]. Mapping to Gene Ontology (GO) [56] terms was performed with the GO.db (2.6.1) package [57]. Microarray data were deposited in the Gene Expression Omnibus under GSE77987.

\section{Abbreviations}

GSEA - Gene Set Enrichment Analysis; DEDS Differential Expression via Distance Summary; NES Normalized Enrichment Score; AML - Acute Myeloid Leukemia; CRC - Colorectal Cancer; CA - Cortistatin A; F - Flavopiridol; IFNa - human type I interferon $\alpha / \beta$; IFNg type II interferon $\gamma$; IER - Immediate Early Response; PO - per os; SC - subcutaneous; CCLE- Cancer Cell Line Encyclopedia.

\section{ACKNOWLEDGMENTS}

Tomasz Rzymski, Agnieszka Dreas, Katarzyna Wiklik, Aniela Gołas, Ewelina Gabor-Worwa, Arkadiusz Białas, Renata Windak, Krzysztof Brzózka are full time employees and stock-holders of Selvita S.A.

\section{CONFLICTS OF INTEREST}

The authors declare that there is no conflicts of interest. 


\section{FUNDING}

The project was co-financed by the European Regional Development Fund under The Operational Program Innovative Economy 2007-2013 measure 1.4-4.1 (UDA-POIG.01.04.00-12-095/09-00 UDAPOIG.04.01.00-12-095/09-00).

MMikula was supported by the National Science Centre grant [2011/01/D/NZ2/05307].

\section{REFERENCES}

1. Knuesel MT, Meyer KD, Bernecky C, Taatjes DJ. The human CDK8 subcomplex is a molecular switch that controls Mediator coactivator function. Genes Dev. 2009; 23: 439-51. doi: 10.1101/gad.1767009.

2. Rzymski T, Mikula M, Wiklik K, Brzózka K. CDK8 kinase - An emerging target in targeted cancer therapy. Biochim Biophys Acta. 2015; 1854: 1617-29. doi: 10.1016/j. bbapap.2015.05.011.

3. Cee VJ, Chen DYK, Lee MR, Nicolaou KC. Cortistatin a is a high-affinity ligand of protein kinases ROCK, CDK8, and CDK11. Angew Chemie Int Ed. 2009; 48: 8952-7. doi: 10.1002/anie.200904778.

4. Pelish HE, Liau BB, Nitulescu II, Tangpeerachaikul A, Poss ZC, Da Silva DH, Caruso BT, Arefolov A, Fadeyi O, Christie AL, Du K, Banka D, Schneider E V, et al. Mediator kinase inhibition further activates superenhancer-associated genes in AML. Nature. 2015; 526:273-6. doi: 10.1038/nature14904.

5. Koehler MFT, Bergeron P, Blackwood EM, Bowman K, Clark KR, Firestein R, Kiefer JR, Maslos K, McCleland ML, Orren L, Salphati L, Schmidt S, Schneider E V, et al. Potent, specific CDK8 kinase inhibitors lack CDK8-dependent antiproliferative activity in HCT-116 colon cancer cell line. ACS Med Chem Lett. 2016; 7:223-8. doi: 10.1021/ acsmedchemlett.5b00278.

6. Poss ZC, Ebmeier CC, Odell AT, Tangpeerachaikul A, Lee T, Pelish HE, Shair MD, Dowell RD, Old WM, Taatjes DJ. Identification of mediator kinase substrates in human cells using cortistatin a and quantitative phosphoproteomics. Cell Rep. 2016; 1-15. doi: 10.1016/j. celrep.2016.03.030.

7. Firestein R, Bass AJ, Kim SY, Dunn IF, Silver SJ, Guney I, Freed E, Ligon AH, Vena N, Ogino S, Chheda MG, Tamayo $\mathrm{P}$, Finn $\mathrm{S}$, et al. CDK8 is a colorectal cancer oncogene that regulates beta-catenin activity. Nature. 2008; 455: 547-51. doi: 10.1038/nature07179.

8. Donner AJ, Ebmeier CC, Taatjes DJ, Espinosa JM. CDK8 is a positive regulator of transcriptional elongation within the serum response network. Nat Struct Mol Biol. 2010; 17: 194-201. doi: 10.1038/nsmb.1752.
9. Donner AJ, Szostek S, Hoover JM, Espinosa JM. CDK8 is a stimulus-specific positive coregulator of p53 target genes. Mol Cell. 2007; 27: 121-33. doi: 10.1016/j. molcel.2007.05.026.

10. Porter DC, Farmaki E, Altilia S, Schools GP, West DK, Chen M, Chang BD, Puzyrev AT, Lim CU, Rokow-Kittell R, Friedhoff LT, Papavassiliou AG, Kalurupalle S, et al. Cyclindependent kinase 8 mediates chemotherapy-induced tumorpromoting paracrine activities. Proc Natl Acad Sci U S A. 2012; 109: 1-6. doi: 10.1073/pnas.1206906109.

11. Fryer CJ, White JB, Jones KA. Mastermind recruits CycC:CDK8 to phosphorylate the Notch ICD and coordinate activation with turnover. Mol Cell. 2004; 16 : 509-20. doi: 10.1016/j.molcel.2004.10.014.

12. Galbraith MDD, Allen MAA, Bensard CLL, Wang X, Schwinn MKK, Qin B, Long HWW, Daniels DLL, Hahn WCC, Dowell RDD, Espinosa JMM. HIF1A employs CDK8-mediator to stimulate RNAPII elongation in response to hypoxia. Cell. 2013; 153: 1327-39. doi: 10.1016/j.cell.2013.04.048.

13. Mallinger A, Schiemann K, Rink C, Stieber F, Calderini M, Crumpler S, Stubbs M, Adeniji-Popoola O, Poeschke O, Busch M, Czodrowski P, Musil D, Schwarz D, et al. Discovery of potent, selective, and orally bioavailable small-molecule modulators of the mediator complex-associated kinases CDK8 and CDK19. J Med Chem. 2016; 1-123. doi: 10.1021/ acs.jmedchem.5b01685.

14. Dale T, Clarke PA, Esdar C, Waalboer D, Adeniji-Popoola O, Ortiz-Ruiz M-J, Mallinger A, Samant RS, Czodrowski P, Musil D, Schwarz D, Schneider K, Stubbs M, et al. A selective chemical probe for exploring the role of CDK8 and CDK19 in human disease. Nat Chem Biol. 2015; 11: 973-80. doi: 10.1038/nchembio.1952.

15. Galbraith MD, Donner AJ, Espinosa JM. CDK8: a positive regulator of transcription. Transcription. 2010; 1: 4-12. doi: 10.4161/trns.1.1.12373.

16. Zhao J, Ramos R, Demma M. CDK8 regulates E2F1 transcriptional activity through S375 phosphorylation. Oncogene. 2013; 32: 3520-30. doi: 10.1038/onc.2012.364.

17. Bancerek J, Poss ZC, Steinparzer I, Sedlyarov V, Pfaffenwimmer T, Mikulic I, Dölken L, Strobl B, Müller M, Taatjes DJ, Kovarik P. CDK8 kinase phosphorylates transcription factor STAT1 to selectively regulate the interferon response. Immunity. 2013; 38: 250-62. doi: 10.1016/j.immuni.2012.10.017.

18. Akoulitchev S, Chuikov S, Reinberg D. TFIIH is negatively regulated by cdk8-containing mediator complexes. Nature. 2000; 407: 102-6. doi: 10.1038/35024111.

19. Berman HM, Kleywegt GJ, Nakamura H, Markley JL. The Protein Data Bank archive as an open data resource. J Comput Aided Mol Des. 2014; 1009-14. doi: 10.1007/ s10822-014-9770-y. 
20. Porter DC, Liang J, Kaza V, Chumanevich AA, Altilia S, Farmaki E, Chen M, Schools GP, Chatzistamou I, Pena MM, Friedhoff LT, Wentland MP, Broude E V., et al. Targeting the seed and the soil of cancers with selective small-molecule inhibitors of CDK8/19: Chemopotentiating, chemopreventive, anti-invasive and anti-metastatic activities. AACR Annual Meeting 2014; April 5-9, 2014; San Diego, CA. 2014.

21. Mallinger A, Crumpler S, Pichowicz M, Waalboer D, Stubbs M, Adeniji-Popoola O, Wood B, Smith E, Thai C, Henley AT, Georgi K, Court W, Hobbs S, et al. Discovery of potent, orally bioavailable, small-molecule inhibitors of WNT signaling from a cell-based pathway screen. J Med Chem. 2015; 58: 1717-35. doi: 10.1021/jm501436m.

22. Schneider E V, Böttcher J, Huber R, Maskos K, Neumann L. Structure-kinetic relationship study of CDK8/CycC specific compounds. Proc Natl Acad Sci U S A. 2013; 110: 8081-6. doi: 10.1073/pnas.1305378110.

23. Wen Z, Zhong Z, Darnell JE. Maximal activation of transcription by Stat 1 and Stat3 requires both tyrosine and serine phosphorylation. Cell. 1995; 82: 241-50.

24. Chao SH, Price DH. Flavopiridol inactivates P-TEFb and blocks most RNA polymerase II transcription in vivo. J Biol Chem. 2001; 276: 31793-9. doi: 10.1074/jbc.M102306200.

25. Baumli S, Lolli G, Lowe ED, Troiani S, Rusconi L, Bullock AN, Debreczeni JE, Knapp S, Johnson LN. The structure of $\mathrm{P}-\mathrm{TEFb}$ (CDK9/cyclin T1), its complex with flavopiridol and regulation by phosphorylation. EMBO J. 2008; 27: 1907-18. doi: 10.1038/emboj.2008.121.

26. Uozumi K, Otsuka M, Ohno N, Moriyama T, Suzuki S, Shimotakahara S, Matsumura I, Hanada S, Arima T. Establishment and characterization of a new human megakaryoblastic cell line (SET-2) that spontaneously matures to megakaryocytes and produces platelet-like particles. Leukemia. 2000; 14: 142-52. doi: 10.1038/ sj.leu.2401608.

27. Amit I, Citri A, Shay T, Lu Y, Katz M, Zhang F, Tarcic G, Siwak D, Lahad J, Jacob-Hirsch J, Amariglio N, Vaisman $\mathrm{N}$, Segal E, et al. A module of negative feedback regulators defines growth factor signaling. Nat Genet. 2007; 39: 503 12. doi: $10.1038 /$ ng 1987.

28. Klampfer L, Huang J, Corner G, Mariadason J, Arango D, Sasazuki T, Shirasawa S, Augenlicht L. Oncogenic Ki-ras inhibits the expression of interferon-responsive genes through inhibition of STAT1 and STAT2 expression. J Biol Chem. 2003; 278: 46278-87. doi: 10.1074/jbc. M304721200.

29. Einav U, Tabach Y, Getz G, Yitzhaky A, Ozbek $\mathrm{U}$, Amariglio N, Izraeli S, Rechavi G, Domany E. Gene expression analysis reveals a strong signature of an interferon-induced pathway in childhood lymphoblastic leukemia as well as in breast and ovarian cancer. Oncogene. 2005; 24: 6367-75. doi: 10.1038/ sj.onc. 1208797 .
30. Subramanian A, Tamayo P, Mootha VK, Mukherjee S, Ebert BL, Gillette MA, Paulovich A, Pomeroy SL, Golub TR, Lander ES, Mesirov JP. Gene set enrichment analysis: a knowledge-based approach for interpreting genome-wide expression profiles. Proc Natl Acad Sci U S A. 2005; 102: 15545-50. doi: 10.1073/pnas.0506580102.

31. Dorsam ST, Ferrell CM, Dorsam GP, Derynck MK, Vijapurkar U, Khodabakhsh D, Pau B, Bernstein H, Haqq CM, Largman C, Lawrence HJ. The transcriptome of the leukemogenic homeoprotein HOXA9 in human hematopoietic cells. Blood. 2004; 103: 1676-84. doi: 10.1182/blood-2003-07-2202.

32. Kroon E, Krosl J, Thorsteinsdottir U, Baban S, Buchberg AM, Sauvageau G. Hoxa9 transforms primary bone marrow cells through specific collaboration with Meis1a but not Pbx1b. EMBO J. 1998; 17: 3714-25. doi: 10.1093/ emboj/17.13.3714.

33. Huang Y, Sitwala K, Bronstein J, Sanders D, Dandekar M, Collins C, Robertson G, MacDonald J, Cezard T, Bilenky M, Thiessen N, Zhao Y, Zeng T, et al. Identification and characterization of Hoxa9 binding sites in hematopoietic cells. Blood. 2012; 119: 388-98. doi: 10.1182/ blood-2011-03-341081.

34. Thorsteinsdottir U, Mamo A, Kroon E, Jerome L, Bijl J, Lawrence HJ, Humphries K, Sauvageau G. Overexpression of the myeloid leukemia-associated Hoxa9 gene in bone marrow cells induces stem cell expansion. Blood. 2002; 99: 121-9. doi: 10.1182/blood.V99.1.121.

35. Clarke PA, Ortiz-Ruiz MJ, TePoele R, Adeniji-Popoola O, Box G, Court W, Czasch S, El Bawab S, Esdar C, Ewan K, Gowan S, De Haven Brandon A, Hewitt P, et al. Assessing the mechanism and therapeutic potential of modulators of the human Mediator complex-associated protein kinases. Elife. 2016; 5. doi: 10.7554/eLife.20722.

36. Tam WF, Hähnel PS, Schüler A, Lee BH, Okabe R, Zhu N, Pante S V, Raffel G, Mercher T, Wernig G, Bockamp E, Sasca D, Kreft A, et al. STAT5 is crucial to maintain leukemic stem cells in acute myelogenous leukemias induced by MOZ-TIF2. Cancer Res. 2013; 73: 373-84. doi: 10.1158/0008-5472.CAN-12-0255.

37. Bose P, Grant S. Mcl-1 as a therapeutic target in acute myelogenous leukemia (AML). Leuk Res Reports. 2013; 2: 12-4. doi: 10.1016/j.lrr.2012.11.006.

38. Barretina J, Caponigro G, Stransky N, Venkatesan K, Margolin AA, Kim S, Wilson CJ, Lehár J, Kryukov G V, Sonkin D, Reddy A, Liu M, Murray L, et al. The Cancer Cell Line Encyclopedia enables predictive modelling of anticancer drug sensitivity. Nature. 2012; 483: 603-7. doi: 10.1038/nature11003.

39. Yang YH, Xiao Y, Segal MR. Identifying differentially expressed genes from microarray experiments via statistic synthesis. Bioinformatics. 2005; 21: 1084-93. doi: 10.1093/ bioinformatics/bti108. 
40. Watari K, Mayani H, Lee F, Dragowska W, Lansdorp PM, Schrader JW. Production of interleukin 1beta by human hematopoietic progenitor cells. J Clin Invest. 1996; 97: 1666-74. doi: 10.1172/JCI118593.

41. Ivanova NB, Dimos JT, Schaniel C, Hackney J, Moore K, Lemischka IR. A stem cell molecular signature. Science. 2002; 298: 601-4. doi: 10.1126/science.1073823.

42. Powell J a, Thomas D, Barry EF, Kok CH, McClure BJ, Tsykin A, To LB, Brown A, Lewis ID, Herbert K, Goodall GJ, Speed TP, Asou N, et al. Expression profiling of a hemopoietic cell survival transcriptome implicates osteopontin as a functional prognostic factor in AML. Blood. 2009; 114: 4859-70. doi: 10.1182/ blood-2009-02-204818.

43. Gerber JM, Smith BD, Ngwang B, Zhang H, Vala MS, Morsberger L, Galkin S, Collector MI, Perkins B, Levis MJ, Griffin CA, Sharkis SJ, Borowitz MJ, et al. A clinically relevant population of leukemic CD34(+)CD38(-) cells in acute myeloid leukemia. Blood. 2012; 119: 3571-7. doi: 10.1182/blood-2011-06-364182.

44. Quek L, Otto GW, Garnett C, Lhermitte L, Karamitros D, Stoilova B, Lau IJ, Doondeea J, Usukhbayar B, Kennedy A, Metzner M, Goardon N, Ivey A, et al. Genetically distinct leukemic stem cells in human CD34- acute myeloid leukemia are arrested at a hemopoietic precursor-like stage. J Exp Med. 2016; jem.20151775. doi: 10.1084/jem.20151775.

45. Meissl K, Macho-Maschler S, Müller M, Strobl B. The good and the bad faces of STAT1 in solid tumours. Cytokine. 2015; doi: 10.1016/j.cyto.2015.11.011.

46. Weichselbaum RR, Ishwaran H, Yoon T, Nuyten DS a, Baker SW, Khodarev N, Su AW, Shaikh AY, Roach P, Kreike B, Roizman B, Bergh J, Pawitan Y, et al. An interferon-related gene signature for DNA damage resistance is a predictive marker for chemotherapy and radiation for breast cancer. Proc Natl Acad Sci U S A. 2008; 105: 18490-5. doi: 10.1073/pnas.0809242105.

47. Khodarev NN, Roizman B, Weichselbaum RR. Molecular pathways: interferon/stat1 pathway: role in the tumor resistance to genotoxic stress and aggressive growth. Clin Cancer Res. 2012; 18: 3015-21. doi: 10.1158/1078-0432. CCR-11-3225.

48. Guinney J, Dienstmann R, Wang X, de Reyniès A, Schlicker A, Soneson C, Marisa L, Roepman P, Nyamundanda G, Angelino P, Bot BM, Morris JS, Simon IM, et al. The consensus molecular subtypes of colorectal cancer. Nat Med. 2015. doi: 10.1038/nm.3967.

49. Putz EM, Gotthardt D, Hoermann G, Csiszar A, Wirth S, Berger A, Straka E, Rigler D, Wallner B, Jamieson AM, Pickl WF, Zebedin-Brandl EM, Müller M, et al. CDK8mediated STAT1-S727 phosphorylation restrains NK cell cytotoxicity and tumor surveillance. Cell Rep. 2013; 43744. doi: 10.1016/j.celrep.2013.07.012.

50. Schepers H, van Gosliga D, Wierenga ATJ, Eggen BJL, Schuringa JJ, Vellenga E. STAT5 is required for longterm maintenance of normal and leukemic human stem/ progenitor cells. Blood. 2007; 110: 2880-8. doi: 10.1182/ blood-2006-08-039073.

51. Birkenkamp K, Geugien M, Lemmink H, Kruijer W, Vellenga E. Regulation of constitutive STAT5 phosphorylation in acute myeloid leukemia blasts. Leukemia. 2001; 15: 1923-31. doi: 10.1038/sj.leu.2402317.

52. Sternberg DW, Gilliland DG. The role of signal transducer and activator of transcription factors in leukemogenesis. J Clin Oncol. 2004; 22: 361-71. doi: 10.1200/ JCO.2004.10.124.

53. Friedbichler K, Kerenyi MA, Kovacic B, Li G, Hoelbl A, Yahiaoui S, Sexl V, Müllner EW, Fajmann S, Cerny-Reiterer S, Valent P, Beug H, Gouilleux F, et al. Stat5a serine 725 and 779 phosphorylation is a prerequisite for hematopoietic transformation. Blood. 2010; 116: 1548-58. doi: 10.1182/ blood-2009-12-258913.

54. Schneider E V, Böttcher J, Blaesse M, Neumann L, Huber $\mathrm{R}$, Maskos $\mathrm{K}$. The structure of $\mathrm{CDK} 8 / \mathrm{CycC}$ implicates specificity in the $\mathrm{CDK} /$ cyclin family and reveals interaction with a deep pocket binder. J Mol Biol. 2011; 412: 251-66. doi: 10.1016/j.jmb.2011.07.020.

55. Paziewska A, Dabrowska M, Goryca K, Antoniewicz A, Dobruch J, Mikula M, Jarosz D, Zapala L, Borowka A, Ostrowski J. DNA methylation status is more reliable than gene expression at detecting cancer in prostate biopsy. Br J Cancer. 2014; doi: 10.1038/bjc.2014.337.

56. Ashburner M, Ball CA, Blake JA, Botstein D, Butler H, Cherry JM, Davis AP, Dolinski K, Dwight SS, Eppig JT, Harris MA, Hill DP, Issel-Tarver L, et al. Gene ontology: tool for the unification of biology. The Gene Ontology Consortium. Nat Genet. 25: 25-9. doi: 10802651.

57. Lin SM, Du P, Huber W, Kibbe WA. Model-based variancestabilizing transformation for Illumina microarray data. Nucleic Acids Res. 2008; 36: e11. doi: 10.1093/nar/gkm1075. 